\title{
Processo Inovativo na Indústria de Software de Joinville (SC): uma análise a partir do marco teórico neo-schumpeteriano ${ }^{1}$
}

\author{
André Tortato Rauen \\ IG-UNICAMP \\ André Tosi Furtado \\ IG-UNICAMP \\ Silvio Antônio Ferraz Cário \\ UFSC
}

Recebido: 27/7/2007 Aprovado: 8/12/2008

\section{Resumo}

Considerando a necessidade de melhor compreender os processos de geração e difusão de inovações em países em desenvolvimento, este trabalho foi confeccionado com o objetivo de analisar a dinâmica inovativa da indústria de software geograficamente circunscrita pelos entornos do município de Joinville (SC). Para tanto, utilizou-se como ferramenta de análise e descrição o arcabouço teórico neo-schumpeteriano de sistemas locais de inovação. A utilização desse arcabouço permitiu mapear as diferentes organizaçôes e instituiçôes de fomento à referida indústria local. Nesse sentido, permite-se falar em sistema local de

\footnotetext{
Tradicionalmente o termo "indústria" está associado à produção física, portanto, tangível de bens. Contudo, este trabalho faz uma licença de linguagem e utiliza esse termo para designar também as firmas existentes no mercado de softwares. Nesse contexto, a "indústria de software" aqui retratada refere-se às atividades listadas nas classes: 7221-4 (desenvolvimento de softwares prontos para uso) e 7229-0 (desenvolvimento de softwares sob encomenda) da Classificação Nacional de Atividades Econômicas - CNAE 1.0. Excepcionalmente em algumas análises feitas ao longo do trabalho, considerou-se também as atividades referentes às classes 7230-3, 7210-9, 7240-0, 7250-8 e 7290-7 da CNAE 1.0. Essa licença se lastreia nas proposições apresentadas por Freire, de que a utilização do referido termo, para designar o lado da oferta do mercado de software, exige que se amplie o conceito de indústria, "para que se possa compreender um conjunto de empresas com um produto característico (neste caso, o software) independente da concepção tradicional de indústria transformadora de matéria-prima para a produção de mercadorias. Isso se faz necessário até pela própria especificidade da matéria-prima nesta indústria, ou seja, por ser constituída basicamente de conhecimento, sendo que seu produto é uma seqüência de linhas de programação, as quais são denominadas 'programas de computador' ou softwares. Não apresenta nada de tangível, ainda que possa ter algum suporte material" (2002:19).
} 
inovação da indústria de software de Joinville. Contudo, como se constatou em entrevistas a firmas selecionadas, trata-se de um sistema ainda imaturo, no qual

1) as firmas pouco interagem entre si e com a pesquisa acadêmica;

2) as leis locais de incentivo ao setor são desconhecidas;

3) o preço da mão de obra qualificada fundamenta em boa medida a competitividade das empresas locais.

Mesmo ainda imaturo, o sistema de inovação identificado possui importantes produtores de software, pacote de significativa inserção nacional e internacional, elevado número de firmas atuantes no segmento de serviços de software e organizações de fomento setorial com relevantes potencialidades para o conjunto do tecido produtivo local.

Palavras-Chave | Inovações; Sistemas Locais de Inovação; Indústria de Software

Códigos JEL | O031; O033; L086

Aвstract

In order to better understand the processes of generation and dissemination of innovation in developing countries, this paper analyzes, based on the neoshumpeterian local innovation system framework, the innovative processes of Joinville's software industry. The use of this framework allowed the identification of many organizations and institutions that promoted the local software industry. In such a way, it was possible to determine the existence of a local innovation system in the software industry of Joinville. However, as noted on the interviews applied to selected firms, this is still an immature system, in which

1) companies barely interact with each other and with academic research;

2) the local legislation of promotion of the industry is unknown;

3) the competitiveness of local companies is based on the price of qualified labor.

Even still immature, the identified innovation system has important Latin-American producers of package software, a large number of firms engaged in the sector of software services and many software organizations with relevant potential for the whole of innovation system.

KEYWORDs | Innovation; Local Innovation Systems; Software Industry

JEL-Codes | O031; O033; L086 


\section{Introdução}

As aglomerações de empresas intensivas em conhecimento têm suscitado relativo interesse tanto por parte de policy makers quanto de acadêmicos, principalmente, quando se discute as novas faces assumidas pelo capitalismo contemporâneo no contexto de um suposto modo de regulação pós-fordista. Contudo, essas aglomerações, ao contrário de se mostrarem uniformes, são em verdade muito distintas umas das outras, algumas inclusive com muito pouco da mística que recobre as discussóes sobre polos, parques, tecnopolos, cidades da ciência, entre outros tantos nomes que evocam modernidade e alta tecnologia.

Essas aglomeraçôes, também presentes em países em desenvolvimento, refletem as dinâmicas internas dos meios nas quais as mesmas estão inseridas. Portanto, suas características podem variar significativamente diante dos preceitos teóricos do moderno mainstream da geografia econômica. Distanciado-se inclusive das constataçôes empíricas realizadas a partir das experiências de países desenvolvidos.

Procurando contribuir para as discussões sobre a dinâmica tecnológica em países em desenvolvimento, o presente trabalho objetiva analisar, através do marco teórico neo-schumpeteriano de sistemas de inovação, o processo inovativo adotado pelas firmas da indústria de software de Joinville (SC). Com esse objetivo, o artigo divide-se, incluindo essa introdução, em seis seções. A segunda seção faz uma revisão bibliográfica das origens neo-schumpeterianas dos sistemas locais de inovação. Dáse ênfase, nesse sentido, ao processo inovativo e às definiçôes e dinâmicas inerentes aos sistemas nacionais de inovação. A terceira seção visa lançar alguma luz sobre a dinâmica setorial do que, neste trabalho, se denominou indústria de software. Aparecem nessa seção, portanto, uma breve trajetória tecnológica do setor, a tipologia selecionada em função dos objetivos do trabalho, bem como o regime tecnológico relativos às atividades de software. Descrevendo três fases históricas distintas, a quarta seção, através de extensa pesquisa bibliográfica, apresenta o surgimento e a consolidação da hoje robusta indústria de software de Joinville. A quinta seção apresenta os resultados de entrevistas realizadas em 2005, com uma amostra selecionada de firmas e demais organizaçôes e destaca o processo inovativo realizado por essas firmas, bem como a relevância das diferentes organizaçôes e instituições para as inovaçôes geradas no sistema estudado. Nesse sentido, o trabalho se encerra apresentando algumas conclusões gerais que chamam a atenção para a limitada interação entre os componentes do sistema selecionado. 


\section{Abordagem neo-schumpeteriana da inovação}

A emergente realidade socioeconômica marcada pela intensa dependência dos fluxos de conhecimento e pela consequente necessidade constante de aprendizado tem provocado profundas mudanças tanto nas firmas, nos indivíduos, quanto nos espaços geográficos em que estes estão inseridos. Sendo assim, dadas as atuais tendências mundiais, espera-se que a prosperidade das regiōes esteja menos relacionada à exploração de recursos naturais e mais à posse de ativos estratégicos, tais como conhecimento, experiência, capacidade e habilidades da mão de obra, e qualidade das instituições que regem as economias (López \& Lugones, 1998:16).

Segundo a corrente neo-schumpeteriana, a geração de novos conhecimentos, que podem ou não levar à criação de inovações, surge através da interação humana e resulta de uma dinâmica sistêmica e não linear. Esse processo só pode ser compreendido, em sua essência, mediante uma abordagem multidisciplinar, que considere a inovação decorrente de um processo socialmente construído, no qual os fluxos de conhecimento são tanto tácitos quanto codificados.

Objetivando compreender em sua totalidade esses fluxos de conhecimento, essa escola do pensamento econômico desenvolve uma categoria de análise denominada sistemas de inovação. Em que pesem as diferentes dinâmicas inovativas encontradas entre regióes e países, essa abordagem tem sido útil para analisar a mudança técnica tanto em países centrais, quanto em países periféricos.

Tradicionalmente, as análises que tratavam da performance tecnológica de uma economia estavam apenas fundamentadas na observação dos inputs (por exemplo, gastos em pesquisa e desenvolvimento) e dos outputs (por exemplo, patentes e licenças) inerentes ao desenvolvimento de novos produtos ou processos (Godin, 2007). Com o passar do tempo, as limitações dessa abordagem tornaram-se evidentes. Essas análises tradicionais, apesar de serem capazes de medir, parcialmente, o volume de esforços e a geração de invençôes, eram insuficientes para a compreensão da capacidade inovativa de uma determinada economia, sobretudo por não tratarem dos fluxos de conhecimento surgidos nos processos de interação existentes entre os agentes econômicos. Nesse contexto, a teoria neo-schumpeteriana procura, diferentemente das abordagens tradicionais, compreender as razões pelas quais o processo de inovação difere segundo as realidades socioeconômicas estudadas. Para tal, o foco da análise neo-schumpeteriana concentra-se na interação social inerente à transformação dos inputs em outputs (OCDE, 1997:9).

De acordo com essa teoria, a inovação só pode ser entendida na condição de um processo dinâmico que foge ao caráter estático da microeconomia neoclássica. 
A dinamicidade desse processo provém dos incessantes feedbacks entre a firma e seu meio, construindo uma base de conhecimento fortemente relacionada aos processos de aprendizagem do tipo learning by interacting. A firma, nesse sentido, é vista não como uma unidade econômica maximizadora de lucro, mas como um repositório de conhecimento. Grosso modo, o desenvolvimento econômico associado ao progresso técnico, segundo a visão neo-schumpeteriana, é "um processo evolucionário no qual alternativas tecnológicas novas competem entre si e com as práticas prevalecentes, com a seleção ex-post que determina os vencedores e perdedores, normalmente com considerável incerteza ex-ante de quem será o vencedor" (Nelson, 1994:50).

Assim, a inovação resulta de um relacionamento socialmente construído, não sendo apenas obra de esforços individuais descontextualizados de um meio ambiente socioeconômico determinado, tanto que, "em geral, o progresso tecnológico procede através do desenvolvimento e exploração tanto de elementos públicos do conhecimento, compartilhados por todos os atores envolvidos em certa atividade, quanto de elementos, privados, locais parcialmente tácitos, específicos à firma e cumulativos do conhecimento" (Dosi, 1982).

O desenvolvimento de inovações, além de ser um processo dinâmico interativo, é também um processo cumulativo, muitas vezes path dependent (dependente do caminho), ou seja, as possibilidades futuras da firma estão forçosamente ligadas ao que ela realizou no passado (Dosi, 1982). Nesse sentido, López e Lugones (1998:5) consideram os processos de inovação como "fortemente tácitos, cumulativos e localizados". A inovação, portanto, é entendida como um constante processo de aprendizado interativo, socialmente e territorialmente enraizado, sendo também culturalmente e institucionalmente contextualizado (Coenen, Moodyson \& Asheim, 2004:2).

$\mathrm{Na}$ medida em que existe intensa interação entre a firma inovadora e o meio no qual ela está inserida, o processo de geração, difusão e uso de novos conhecimentos, produtos ou serviços deve ser analisado sob uma perspectiva sistêmica, cujas fronteiras de análise sejam traçadas em razão da pertinência das relações inerentes a esse sistema.

Surge, nesse contexto, o conceito de sistemas nacionais de inovação, o qual relaciona a performance inovativa de um país à sua capacidade de integrar diferentes atores: empresas privadas, universidades e organizaçōes públicas e privadas de pesquisa, agências de fomento e governo, entre outras. Tal performance varia de acordo com a capacidade desse sistema em formar um denso tecido de interações baseado na construção coletiva de conhecimento, proveniente tanto da criação compartilhada de novas tecnologias quanto de seu uso. 


\subsection{Sistemas de nacionais de inovação}

Muito embora List (1841), no século XIX, já antecipasse boa parte dos elementos que hoje constituem o arcabouço neo-schumpeteriano inerente aos estudos da ciência, tecnologia e economia no interior do Estado-nação, é Freeman (1987:1) que, pela primeira vez, formulou o conceito de sistema nacional de inovação, sendo assim definido como "uma rede de instituições nos setores público e privado cujas atividades e interaçōes iniciam, importam, modificam e difundem novas tecnologias".

As abordagens baseadas nos sistemas nacionais de inovação refletem a crescente atenção dada ao papel do conhecimento no desenvolvimento econômico atual. Nessa forma de análise, o foco se concentra no mapeamento dos fluxos de conhecimento, como complemento à mensuração dos inputs e outputs explicitamente discriminados. Por serem tácitos, esses fluxos de conhecimento são de mais difícil mensuração. Assim, o referencial analítico presente nos sistemas de inovação pretende caracterizar os principais canais pelos quais flui o conhecimento - tanto nos níveis supranacionais, nacionais, quanto subnacionais - e identificar gargalos que obstaculizam essa interação para sugerir políticas e ações que possam tornar esses canais cada vez mais fluidos. Nesse sentido, trata-se de identificar as relações e as conexóes inerentes à produção científica e tecnológica que existem entre indústria, governo e academia (OECD, 1997:11). Essas relaçōes e conexões já haviam sido abordadas anteriormente por Sábato e Botana (1968), ao referirem-se especificamente ao contexto dos países latino-americanos. Os três polos que formam o "Triângulo de Sábato" careciam de elos, especialmente entre a vertente da infraestrutura científica e o aparelho produtivo, devido à forte dependência tecnológica das empresas, que recorriam ao fluxo externo de conhecimento.

Para Lundvall (1992), o foco da análise está nos processos de interação, relacionados inclusive ao uso de novas tecnologias - que transcendem as relações entre organizações e instituições diretamente envolvidas na geração de novos produtos e processos -, e passa a incorporar os subsistemas produtivos, de marketing e financeiros. Assim sendo, conforme o autor, um sistema nacional de inovação pode ser definido como "os elementos e as relações que interagem na produção, difusão e uso de novos e economicamente úteis conhecimentos [...] localizados tanto dentro, quanto apenas enraizados, nas fronteiras de um Estado-nação" (Lundvall, 1992:2).

A relevância dos sistemas nacionais como fundamento nos quais se baseiam as políticas públicas de fomento à inovação está descrita em Metcalfe (1995). Para esse autor, um sistema nacional de inovação 
"é aquele universo de diferentes instituiçōes que, em conjunto ou individualmente, contribuem para o desenvolvimento e a difusão de novas tecnologias e que fornecem a estrutura dentro da qual os governos formam e implementam politicas que influenciam o processo de inovação tecnológica. Como tal, é um sistema de instituiçôes interligadas para criar, armazenar e transferir o conhecimento, as habilidades e os artefatos que definem novas tecnologias" (Metcalfe, 1995:38).

As dinâmicas inerentes ao funcionamento dos sistemas nacionais de inovação descritas na literatura contemporânea são até certo ponto facilmente verificadas em países desenvolvidos. Porém a utilização do marco conceitual dos sistemas nacionais de inovação não pode ser realizada indiscriminadamente, quando da análise de sistemas de inovação de países em desenvolvimento. $\mathrm{Na}$ medida em que esses países possuem distintas características socioeconômicas, a utilização dos conceitos inerentes aos sistemas nacionais de inovação deve considerar a existência dessas discrepâncias. A análise desenvolvida por autores latino-americanos, como Sábato e Botana (1968) e Herrera (1971), postula que o nível e a qualidade das interações entre os principais atores dos sistemas nacionais de inovação sempre foram limitados nesses países, por conta da excessiva dependência do fluxo externo de tecnologia. Essa corrente afirma, contrariamente à corrente neo-schumpeteriana, que a importação de tecnologia inibe os elos inovativos dentro do sistema nacional de inovação. Reflexões mais recentes elaboradas por autores latino-americanos relativas ao período de abertura econômica da década de 90 do século XX reiteram o trade-off que se estabelece entre o fluxo externo e interno de tecnologia (Katz \& Stumpo, 2001).

Essas limitações de interação dentro do sistema nacional não retiram a validade do conceito, mas diferenciam a natureza dessas interações quando ele é aplicado a países em desenvolvimento. Nesse sentido, dando um passo adicional para adequar o conceito a países em desenvolvimento, Albuquerque (1999) propõe que os sistemas nacionais de inovação sejam separados em três grupos distintos; são eles:

1) sistemas maduros;

2) sistemas catching-up;

3) sistemas não maduros.

No grupo dos sistemas maduros, encontram-se os sistemas nacionais de países desenvolvidos membros da OCDE, como Japão, Estados Unidos, Reino Unido, Itália, entre outros, nos quais as dinâmicas inerentes ao processo inovativo descrito no 
arcabouço teórico correspondem de certa forma com a realidade estudada. Nesses países, existe interação entre as organizações que compõem o sistema, comprometimento das firmas com atividades inovativas e geração interna - ao sistema - de conhecimentos. Já no segundo grupo estão os sistemas chamados pelo autor de catching-up, os quais se constituem em sistemas intermediários. Esses sistemas se encontram em países nos quais o crescimento dos indicadores de ciência e tecnologia e a velocidade de difusão de novos conhecimentos permitem afirmar que há certo grau de convergência com o nível de desenvolvimento tecnológico dos países desenvolvidos. Entretanto, nesse segundo grupo, ainda existem, principalmente, problemas relacionados à geração interna de conhecimentos. Esse grupo é composto por países asiáticos de rápido crescimento econômico, quais sejam: Coreia do Sul, Singapura e Taiwan.

O terceiro grupo, de sistemas não maduros, pode, por sua vez, ser subdividido em três subgrupos, a saber:

1) OISTS - old and ineffective science and technology structure, nesse grupo estão os países da América Latina, Índia e África do Sul;

2) ECEC - Eastern and Central European countries, esse conjunto é composto pelos sistemas nacionais dos antigos países comunistas, com destaque para o sistema russo - construídos com foco na ciência -, que hoje sofrem com a incapacidade de transformar os conhecimentos técnico-científicos em inovações;

3) finalmente, tem-se o conjunto de sistemas nacionais de inovação chamados de Asia cubs, nesse grupo encontram-se sistemas de países asiáticos, que não podem ser considerados sistemas catching-up, mas são distintos dos sistemas chamados de OISTS e ECEC. Esse conjunto abarca os sistemas ainda em fase de construção com pouca estrutura científica, cujos representantes são Indonésia, Malásia, Filipinas e Tailândia. ${ }^{2}$

Dados os objetivos do presente trabalho, torna-se necessário focar a atenção no grupo de sistemas nacionais de inovação denominados sistemas de estrutura científica e tecnológica velha e ineficiente ${ }^{3}$ - OISTS, em sua sigla em inglês. Nesses países, e de uma maneira geral nos países não membros da OCDE, a estrutura de C\&T existente volta-se apenas para a construção de competências que permitem

2 Existe ainda na tipologia proposta por Albuquerque (1999) o grupo denominado "outros", que inclui Turquia, China e Paquistão, países que, segundo o autor, são de difícil enquadramento em sua tipologia.

3 Ineficiente do ponto de vista puramente econômico, uma vez que a estrutura de ciência e tecnologia de um país ultrapassa a simples busca por inovações. 
ao país ser capaz de se inserir nos fluxos de conhecimento internacionais, visando a processos de transferência de tecnologia. Dessa forma, a função desempenhada pela ciência e tecnologia, produzida nos países periféricos, é a de ligar o sistema nacional de inovação à dinâmica científica e tecnológica internacional num processo marcado pela busca de capacidade de absorção (absorptive capability), em vez da geração própria de novo conhecimento (Albuquerque, 1999). Assim, os sistemas nacionais de inovação de países em desenvolvimento, ou seja, todos que não se enquadram no conceito de maduros, procuram, diferentemente do que se subentende da literatura dominante, produzir ciência e tecnologia segundo a concepção de países mais desenvolvidos.

A análise dos indicadores de ciência e tecnologia dos sistemas de inovação do grupo OISTS mostra a existência de uma infraestrutura de C\&T e de um certo nível de investimentos em $\mathrm{P} \& \mathrm{D}$. Contudo, os investimentos em $\mathrm{P} \& \mathrm{D}$, em porcentagem do PIB nesses países, são inferiores aos verificados nos sistemas maduros e catching-up. Ocorre, pois, que, no grupo OISTS, os sistemas nacionais são marcados pela falta de interações entre os componentes e pelo baixo comprometimento das firmas com atividades de pesquisa, conformando um processo inovativo quase sempre determinado pela imitação.

A dinâmica da inovação nos países em desenvolvimento é, portanto, distinta da dos países desenvolvidos. Essa dinâmica está condicionada pelo forte peso que a transferência internacional de tecnologia exerce na mudança tecnológica local. É comum que o desenvolvimento local de tecnologias seja substituído pelo treinamento externo, que a importação de equipamentos seja preferida à construção interna e que o treinamento nacional dos quadros de pesquisadores seja substituído pela participação em programas de pós-graduação estrangeiros. Entretanto, ao lado do fluxo externo de tecnologia, existe uma importante geração de tecnologia incremental, abundantemente tratada pela chamada literatura "incrementalista" (Bell, 1984; Katz, 1987; Lall, 1982). A geração de tecnologia local, que visa, sobretudo, ao aperfeiçoamento e à adaptação da tecnologia importada, decorre de esforços realizados internamente nas unidades produtivas, no chão de fábrica ou pelo departamento de engenharia. Existem poucos elos entre as empresas e, sobretudo, entre estas e as instituiçóes de pesquisa com vistas ao desenvolvimento de novas tecnologias.

Portanto, o modus operandis da C\&T voltada à inovação nos países periféricos não se encaixa perfeitamente no que é descrito pelo arcabouço teórico tradicional de sistemas nacionais de inovação. Disso decorre que esse arcabouço e sua variante regional/local só podem ser utilizados na análise de realidades próprias de países 
em desenvolvimento como o Brasil, na medida em que se considere que na periferia do sistema capitalista existem distintos graus de desenvolvimento tecnológico, econômico e social, os quais, em conjunto ou isoladamente, conformam uma dinâmica tecnológica não tão próxima da literatura quanto o que se verifica em países desenvolvidos. Assim, espera-se encontrar, nesses sistemas nacionais não maduros, sistemas regionais/locais de inovação cuja dinâmica interna reproduza, numa escala espacial mais restrita, as principais características associadas ao processo inovativo no nível nacional.

Os sistemas de inovação podem ser supranacionais, nacionais ou subnacionais (regionais ou locais), e ao mesmo tempo também podem ser setoriais com todas essas variantes geográficas. O que define se um sistema de inovação deve ser delimitado espacialmente ou setorialmente, ou de ambas as formas, é seu objeto de estudo. Todas as variantes do conceito são úteis, mas devem ser consideradas apenas quando relevantes à realidade estudada (Edquist, 1997:12). O presente trabalho buscou utilizar tanto um recorte espacial - a cidade de Joinville -, quanto um recorte setorial - a indústria de software -, tratando o objeto de estudo sob a perspectiva de um sistema local de inovação de determinado setor econômico.

\subsubsection{Sistemas locais de inovação}

Compartilhando boa parte da dinâmica e lógica de funcionamento dos sistemas nacionais, mas partindo de uma unidade analítica menos agregada, tem-se os sistemas regionais/locais de inovação (Ashein, 1995; Cooke, 1996, 2003; Maskell \& Malmberg, 1999). Para Cooke (2003:9), a abordagem conceitual de sistemas regionais/locais de inovação possui como premissa básica "o fato de que muitas firmas inovativas operam no interior de redes regionais, cooperando e interagindo não apenas com outras firmas, tais como, fornecedores, clientes e concorrentes, mas também com organizações de pesquisa e tecnologia, agências de fomento à inovação, fundos de venture capital, bem como agências governamentais locais e regionais".

Concomitante ao desenvolvimento das definições de sistemas regionais/ locais de inovação por parte dos autores citados anteriormente, tem-se outro grupo de pesquisadores que se preocupa com o estudo da inovação a partir de um recorte setorial e/ou tecnológico. Autores como Carlsson e Stankiewicz (1994), Breschi e Malerba (1997), Carlsson e Jacobson (1997) e Nelson e Mowery (1999) cunham o termo sistemas tecnológicos, sistemas estes definidos "como uma rede de agentes interagindo em uma área econômica/industrial sobre uma infraestrutura 
institucional particular ou um conjunto de infraestruturas envolvido na geração, difusão e utilização de tecnologia" (Carlsson \& Stankiewicz, 1995:111). É importante ressaltar que as discussōes sobre sistemas tecnológicos são o substrato teórico-analítico no qual se sustenta o conceito de sistema setorial de inovação.

De maneira geral, os sistemas de inovação, tanto nacionais quanto locais/ regionais, são formados por dois elementos essenciais distintos, porém complementares, quais sejam: as organizações e as instituiçôes. Cabe ressaltar que muitos autores que tratam dos sistemas de inovação não fazem qualquer distinção entre esses dois elementos e, por via de regra, os chamam apenas de instituiçôes. No entanto, Edquist (1997), evidentemente influenciado pelas ideias de North (1990), promove uma discussão sobre os elementos essenciais a partir dos quais os sistemas de inovação se constituem.

Assim, tem-se as organizações definidas como estruturas formais conscientemente criadas com objetivos explícitos (North, 1990, as chama de jogadores de um sistema). As organizações são, muitas vezes, pessoas jurídicas que agem dentro de um sistema de inovação. Elas podem possuir pessoal especializado em pesquisa e desenvolvimento e algumas delas trabalham visando à interação entre os demais agentes que compõem o sistema. Podem ser públicas ou privadas. Incentivam, testam, produzem e difundem ideias inovadoras. Constituem-se em criações sociais conscientes com razão prática e clara de ser.

As organizações que compõem um sistema local de inovação são

1) organizações produtivas (privadas - firmas - ou públicas);

2) organizações de ensino e pesquisa;

3) organizações financeiras (bancos de fomento e venture capital);

4) organizações de comércio interno e externo;

5) organizaçōes públicas (prefeituras e secretarias);

6) organizações de coordenação de classe (sindicatos patronais e trabalhistas);

7) organizaçōes de infraestrutura comum (serviços básicos e de provimento de informaçôes);

8) organizações de fomento setorial.

Por sua vez, as instituições são responsáveis pela intermediação das atividades realizadas nas organizaçōes, que podem criar uma sensação de segurança entre os agentes e, por isso, possibilitar a diminuiçãao dos riscos inerentes ao processo inovativo. Nesse contexto, as instituições - que são forjadas sob traços culturais comuns - 
determinam, através da repetição contínua de procedimentos, certo grau de previsibilidade quanto às ações dos agentes que compõem um sistema, favorecendo, assim, os necessários processos de interação e cooperação entre as organizações. Segundo North (1990), as instituiçôes reduzem o grau de incerteza e os custos associados à atividade econômica, fato este que torna possível a coordenação dos agentes e a operação eficiente dos mercados (Velasco \& Cruz, 2003:108). Por outro lado, as instituiçôes podem, por vezes, constituir-se em importantes restrições impostas aos agentes econômicos, dificultando ao invés de auxiliar no processo inovativo (Galípolo \& Fernandes, 2005:5).

Na concepção de North (1990), as instituições podem ser formais ou informais, notadamente as primeiras dizem respeito ao que está positivamente estabelecido e as últimas, aos costumes e às tradições tacitamente construídas. Nesse sentido, as instituiçōes mais relevantes são:

1) regulação em marcas e patentes;

2) processos de certificação;

3) rotinas produtivas;

4) contatos formais e informais;

5) cultura e costumes locais e/ou setoriais;

6) políticas de fomento à inovação (em forma de leis ou não);

7) políticas de fomento ao desenvolvimento local de cunho geral (Edquist, 1997).

A interação entre as organizações existentes no interior de um sistema de inovação é, portanto, facilitada pelo entorno institucional. Quando existe o compartilhamento de regras e linguagens entre os principais atores do sistema, os riscos inerentes aos processos mercadológicos envolvendo organizações heterogêneas, porém interdependentes, reduzem-se substancialmente, uma vez que, em virtude das instituições, cada organização pode prever a priori o comportamento dos agentes que compõem esse sistema. As instituições podem num contexto de sistemas de inovação, por assim dizer, lubrificar as engrenagens dos elos que compóe o processo inovativo.

As organizaçōes funcionam, por conseguinte, inseridas num meio institucional determinado, ora sendo influenciadas pelas instituiçōes, ora as influenciando. Apesar da complexidade dessas relações, a interação entre as organizaçôes - e destas com as instituições - constitui importante mecanismo de fomento à criação de inovações 
no interior de um sistema de inovação. Assim sendo, a especificidade local, aliada às características setoriais, determina o ambiente institucional, no qual as firmas, as universidades, as instituições públicas e privadas de pesquisa e as demais organizações estão imersas.

\section{Dinâmica setorial da indústria de software}

Software diz respeito a um conjunto de comandos que deve ser executado por um aparato físico ou uma máquina - também chamado de hardware - com o objetivo de realizar determinadas tarefas. Dito de outra forma, software é um sistema de linhas de programação criado para flexibilizar o funcionamento dos equipamentos eletrônicos (Nicolau, Campos \& Cario, 2000:12). Historicamente, o desenvolvimento dos softwares esteve restrito ao universo das empresas produtoras de hardware. A separação entre software e hardware ainda era incipiente, quando, no período compreendido entre o início da década de 60 e meados da década de 70 do século XX, as linhas de programação passam lentamente a ser dissociadas da produção de hardware. Contudo, a partir do que afirma Steinmuller (1996), a gênese da indústria de software talvez possa ser datada no ano de 1957 com a criação da linguagem de programação FORTRAN, ainda numa fase marcada pela forte ligação entre os bens intangíveis (softwares) e os aparelhos físicos (hardwares). ${ }^{4}$

Apesar de nascer incondicionalmente atrelada ao desenvolvimento dos primeiros hardwares, a indústria de software adquire independência e passa a estar virtualmente presente em todas as atividades econômicas, justificando inclusive as afirmações de que estas, com outros setores intensivos em conhecimento, se constituem no atual vetor de crescimento das economias capitalistas desenvolvidas.

No contexto da trajetória tecnológica, a década de 70 do século XX marca o crescimento do setor de software já como uma indústria independente, para que, com a miniaturização dos componentes físicos (hardwares) - ocorrida no começo da década de 80 do respectivo século - e com o advento do microcomputador, esta se consolide definitivamente.

4 Em 1957, surgia uma linguagem de programação (software) confiável e compartilhada entre os usuários da época, o FORTRAN. Posteriormente, em 1962, a IBM ofereceria em seu hardware série 1401 outra linguagem, o COBOL, esta especialmente adaptada às relações mercantis. Mesmo assim, as linguagens de programação da época ainda não se constituíam em serviços totalmente comercializáveis e era comum que os softwares fossem desenvolvidos de maneira compartilhada entre os usuários, e seu desenvolvimento estava muito associado às empresas produtoras de hardware, notadamente a IBM. Com a progressiva utilização dos softwares nas mais variadas atividades econômicas, a produção das linhas de programação passa lentamente a se dissociar da produção dos aparelhos físicos (hardwares), ganhando contornos próprios (Steinmuller, 1996). 
Dentre as diferentes maneiras de se classificar um software, ${ }^{5}$ destaca-se, dado o objetivo do presente trabalho - analisar o processo inovativo no interior das firmas -, aquela que classifica esse bem em função de sua forma de comercialização. Nesse sentido, os softwares podem ser

1) pacote (vendido em prateleiras a um grande número de clientes anônimos);

2) embarcado (softwares embutidos em equipamentos eletrônicos, por exemplo, celulares, geladeiras, relógios, máquinas industriais entre outros);

3) customizável (grosso modo, são softwares pacote que possuem uma determinada base comum de programação que pode ser adaptada às necessidades de um grupo particular de clientes);

4) por encomenda (são serviços de software que se constituem em linhas de programação cujo processo de produção se dá através de encomendas diretas tanto de consumidores finais ou intermediários, como, por exemplo, outras empresas de software a montante da cadeia produtiva).

O padrão de concorrência da indústria de software varia conforme o segmento de mercado. Considerando os dois tipos extremos, pode-se afirmar que o segmento de software produto - em especial o subgrupo de softwares pacote - se caracteriza por ser altamente concentrado, no qual os investimentos em P\&D são significativos, os canais de distribuição relevantes e o marketing fundamental. Esse segmento é marcado pela presença de monopólios e oligopólios dificilmente reversíveis. Nesse contexto, "ganham relevância, então, os gastos com estrutura de distribuição, publicidade e ações que visam disseminar o uso do produto o mais rápida e amplamente possível, buscando os efeitos da inércia [...] do mercado" (Simioni, 2001:46). Uma vez totalmente difundido, o software passa a estabelecer nos agentes grande dependência, pois, na medida em que este se torna a base para a produção de outros softwares, o abandono de uma plataforma determinada implicaria um elevado custo ao usuário, exercendo, assim, importantes efeitos de lock in. ${ }^{6}$

Já os serviços de software (softwares por encomenda) necessitam de uma relação intensa entre usuário e produtor, uma vez que são requeridos conhecimentos outros que não apenas das atividades de informática. Ou seja, há que se conhecer, com algum grau de profundidade, a área na qual o software será empregado, o que requer

5 Sobre classificações de softwares ver, por exemplo, Nicolau, Campos e Cário (2000), Simioni (2001) e Salatti (2005).

6 Roveré (2006) faz uma interessante e didática apresentação dos efeitos de lock in e inércia através da utilização de exemplos amplamente conhecidos na história da tecnologia e que podem melhor exclarecer a dinâmica econômica associada aos softwares pacote. 
constantes visitas tanto para a criação de linhas de programação, quanto para sua aplicação. Nesse segmento, confiança e cooperação entre fornecedores e consumidores são, portanto, fundamentais. Dada essa maior necessidade de aproximação, as possibilidades comerciais das pequenas e médias firmas diante das grandes parecem ser melhores do que é verificado no mercado de softwares pacote.

Breschi e Malerba (1997) afirmam que o regime tecnológico da indústria de software é marcado por

1) alta oportunidade;

2) alta cumulatividade.

Considerando as inúmeras opçôes tecnológicas e o caráter ainda recente dessa indústria, as firmas de softwares possuem toda uma variedade de caminhos possíveis a seguir. Os potenciais campos de atuação, bem como as muitas possibilidades de desenvolvimento em atividades já estabelecidas, permitem falar em uma indústria com altas oportunidades tecnológicas. Por outro lado, a capacidade das organizações inovadoras de se apropriar dos benefícios econômicos da introdução de novos produtos e novos serviços vai depender da velocidade e das características dessas inovaçôes. Essas organizaçôes buscam fomentar um processo de lock in através do qual o usuário incorrerá em custos crescentes, caso decida abandonar os seus produtos e/ou serviços. Isso ocorre porque, nesse mercado em especial, as inovações desenvolvidas por outras empresas podem constituir-se na base na qual as empresas usuárias realizam suas atividades, tornado-as, dessa forma, "prisioneiras" do produto que consomem. As inovaçôes desenvolvidas pelas últimas estão relacionadas às inovaçōes das primeiras. Nesse cenário ideal de rápida introdução de inovaçōes interrelacionadas e interdependentes, pode-se afirmar que existe elevada apropriabilidade dos ganhos econômicos das inovaçôes, principalmente daquelas que se constituem na base do processo produtivo para as empresas consumidoras. Por outro lado, cenários ideais estão longe da realidade. A facilidade de cópia, aliada ao desrespeito às leis de propriedade intelectual, dilui os ganhos advindos da inovação e cria um mercado informal, no qual os direitos de propriedade são ignorados. Nesse caso específico, há uma baixa apropriabilidade.

O que se pode afirmar concretamente em relação à apropriabilidade na indústria de software é que ela irá depender da capacidade da firma de introduzir inovaçôes que criem efeitos de aprisionamento e de sua capacidade em evitar cópias ilegais, seja através de mecanismos técnicos, seja no campo jurídico-econômico. 
A elevada cumulatividade da inovação tecnológica da indústria de software está associada ao alto grau de complexidade tecnológica incorporada nos produtos e serviços dessa indústria. Dessa forma, os desenvolvimentos presentes dependem significativamente do que foi produzido no passado, ou seja, as linhas de programação, constantemente atualizadas, desenvolvem-se sobre uma base de conhecimentos já existente. O fato essencial da indústria de software é que ela produz novos produtos e serviços que sempre podem ser atualizados, incrementados ou expandidos sobre um determinado estoque de conhecimentos, que, por sua vez, se expande em função do que já foi acumulado. Assim, quanto maior for esse estoque de conhecimentos, tanto maior será a capacidade da firma de software em inovar.

$\mathrm{Na}$ medida em que, nas atividades de programação, o processo inovativo é marcado pela intensa complexidade, elevada multidisciplinaridade e consequente elevado custo relativo e risco, o papel das organizações de ensino e pesquisa seria o de formar mão de obra qualificada diretamente relacionada às necessidades produtivas das firmas e o de prover ao meio em que elas estão inseridas informações, conhecimentos e serviços técnicos especializados. Isso se deve tanto ao fato de que nenhuma firma de software possui, de maneira isolada, todos os conhecimentos técnicos e científicos necessários ao processo de inovação quanto à existência de falhas de mercado, que, por exemplo, podem impedir que os agentes econômicos invistam um volume de recursos considerado socialmente desejável nas atividades em questão. ${ }^{7}$

A interação entre as empresas de software e as organizações de ensino e pesquisa permite que fluxos de conhecimentos pertinentes transcendam os muros da academia e cheguem às empresas seja em forma tácita, incorporada na mão de obra formada, seja por meio de contatos formais ou informais. Esses fluxos de conhecimento, na realidade, fluem tanto da firma para a academia quanto da academia para a firma. Eles permitem que novos produtos e/ou processos sejam desenvolvidos, os quais podem ser utilizados por ambas as organizaçôes. O raciocínio subjacente a essa dinâmica é o de que as organizaçôes de ensino e pesquisa provêm às organizaçôes produtivas (firmas) pessoal qualificado, novos conhecimentos e descobertas, recebendo em troca questôes científicas, colaboração na formação de seus quadros e instrumentos técnicos específicos. Para as firmas, interagir com o meio acadêmico pode significar reduzir custos e riscos, passar a ter acesso simultâneo a novos avanços

7 Dada a ausência de garantias reais em virtude de os ativos dessas empresas concentrarem-se apenas em estoques de conhecimento, a falha de mercado mais relevante associada às empresas de base tecnológica - EBTs refere-se às dificuladades de obtenção de financiamento. Sobre os determinantes do fomento às atividades realizadas pelas EBTs, ver, por exemplo, Colombo e Delmastro (2002). 
científicos e ter à disposição uma ampla infraestrutura destinada à pesquisa, bem como mão de obra qualificada.

Nesse contexto, o papel das universidades e dos centros de pesquisa para indústrias intensivas em conhecimento, tal como a indústria de software, é fundamental. Segundo Castells e Hall (1994) e Benko (1996, 1998), a função das organizações de ensino e pesquisa em concentrações geográficas de atividades econômicas de intensa complexidade tecnológica está relacionada à articulação com as empresas dos setores produtivos de alta tecnologia existentes nas proximidades. Exigindo, portanto, além da formação dos quadros de pessoal técnico, construção e difusão de conhecimentos tecnológicos úteis ao meio que as cercam. Assim, na literatura contemporânea que trata das concentrações de alta tecnologia, evidencia-se a participação ativa das organizações de ensino e pesquisa na formação do conjunto territorial de produção, e as possibilidades produtivas das firmas estão, em algum grau, associadas aos avanços científicos e tecnológicos alcançados nas próprias universidades e centros de pesquisa desse conjunto territorial.

A experiência internacional, notadamente de países centrais, mostra que a capacidade de inserção nos fluxos de comércio mundiais das firmas intensivas em conhecimento está relacionada, dentre outros elementos, às relações formais e informais incorridas nas organizaçôes de ensino e pesquisa. Com base nisso, pode-se, grosso modo, afirmar que as concentraçóes de empresas intensivas em conhecimento pelo menos em países desenvolvidos - são marcadas pela participação ativa das universidades e centros de pesquisa na difusão de informação relevante ao processo produtivo. Essas concentrações se inserem em uma dinâmica espacial marcada pelo relacionamento virtuoso entre a academia e a indústria. Relacionamento este que não apenas forma mão de obra, mas também cria e difunde conhecimento.

Mesmo que as concentrações de empresas de base tecnológica ou de software existentes em países em desenvolvimento como o Brasil não sejam tão complexas e completas quanto o são em países centrais, percebe-se que, apesar da ausência de coordenação nacional, as firmas dessas aglomeraçōes crescem a um ritmo considerável, inclusive diante das atividades tradicionais.

Nesse sentido, com base em Stefanuto (2004), pode-se sumarizar, muito brevemente, a trajetória recente da indústria brasileira de software em seis fatos estilizados, quais sejam:

1) forte dinamismo econômico do setor;

2) aumento da participação dos produtos importados na confecção dos softwares 
nacionais (aumento da participação dos softwares desenvolvidos no exterior por empresas estrangeiras);

3) alteração significativa das capacitações requeridas na indústria;

4) queda dos preços relativos dos equipamentos informáticos e disseminação da Internet;

5) ausência de um projeto nacional para o setor com redução da participação estatal;

6) domínio do mercado interno pelas ETNs (Empresas Transnacionais), cuja participação nele, em 2001, era da ordem de 80\%, com fortes tendências de crescimento.

No ano de 2001, com um mercado interno estimado em US\$ 7,7 bilhões (SOFTEX/MIT, 2003:20), as vendas relacionadas à indústria de software no Brasil eram, em porcentagem do PIB, da ordem de $1,5 \%$ e estão à frente, em termos relativos, da China e da Irlanda (empresas nacionais) e atrás dos Estados Unidos, da Alemanha e do Japão. Estimativas mais recentes mostram que a indústria brasileira de software atingiu, no ano de 2004, o montante de US\$ 8,3 bilhões (SOFTEX, 2005:10). ${ }^{8}$ Considerando que o PIB brasileiro foi, em 2004, segundo o Banco Mundial (2008), da ordem de US\$ 664 bilhōes, pode-se afirmar que, no referido ano, o mercado de software nacional representou $0,8 \%$ de toda a riqueza produzida no país.

\section{Gênese e consolidação da indústria joinvillense de software}

Colonizada majoritariamente por alemães, ainda no século XIX, e inicialmente dependente da produção de bens agrícolas, a atual Joinville, localizada no nordeste catarinense, é a cidade mais populosa do estado, com 487.003 habitantes em 2007. Nesse mesmo ano, o seu PIB atingiu R\$9,1 bilhōes (IBGE, 2008). Dados referentes a 2005 mostram que, do valor adicionado do município, 53,09\% eram provenientes dos serviços, 46,65\%, da indústria ${ }^{9}$ e $0,249 \%$, das atividades agropecuárias (IBGE, 2008). Seu PIB per capita foi, em 2005, de R $\$ 18.785,00$, enquanto este não passava de $\mathrm{R} \$ 11.658,00$ para o conjunto do país (IBGE, 2007). De acordo com o Programa das Nações Unidas para o Desenvolvimento - PNUD, a região metropolitana de

8 É importante ressaltar que muitos dos dados referentes à indústria brasileira de software consideram atividades outras que não as tipicamente de desenvolvimento de linhas de programação. Assim, eles devem ser considerados com certa cautela, na medida em que o objeto de estudo deste trabalho se insere apenas na realidade das firmas desenvolvedoras de software.

9 Com notória concentração no setor eletrometal-mecânico, como demonstra Stallivieri (2004). 
Joinville ${ }^{10}$ atingiu, no ano de 2003 , a segunda posição nacional no ranking do índice de desenvolvimento humano - IDH de 0,85 -, à frente do IDH de 0,75 calculado para o Brasil como um todo ${ }^{11}$ (PNUD, 2003).

Segundo Rocha (1997:13), o processo de industrialização de Joinville, que se iniciou ainda no Brasil império, foi além das demandas geradas pelo setor agrícola da região, cujo principal produto era a erva-mate. Nesse sentido, a mão de obra imigrante proveniente da Alemanha era constituída em boa medida por famílias que possuíam importantes habilidades técnicas. Nos fluxos de imigração que se intensificaram no período compreendido entre os anos de 1850 e 1888, imigraram artesãos, profissionais liberais e pessoas com certo nível de conhecimento dos processos industriais. Muitos desses imigrantes que povoaram boa parte do nordeste catarinense possuíam conhecimentos inerentes às práticas metais-mecânicas desenvolvidas ainda na Europa. Dados os laços familiares e profissionais ainda mantidos, as relaçóes da recém-fundada Joinville eram mais intensas com a Alemanha do que com o Império brasileiro, assim, significativa parte das obras de infraestrutura ou ações econômico-comerciais executadas na antiga Joinville eram tratadas primordialmente com empresas e indivíduos alemães, que, por sua vez, prestavam consultorias ou se estabeleciam na colônia. ${ }^{12}$

Com o declínio da produção de erva-mate, as atividades industriais, que emergiram primeiramente para atender uma tímida demanda por máquinas e equipamentos destinados à produção do setor primário, diversificam-se, devido, em boa medida, ao fortalecimento da economia brasileira através da industrialização por substituição de importações, a ponto de se consolidar, já na primeira metade do século XX, como uma robusta indústria produtora de bens eletrometal-mecânicos. Assim, os processos históricos ocorridos em Joinville - extração da erva-mate, a consequente necessidade de máquinas e equipamentos elétricos (inseridos no contexto de urbanização e industrialização brasileiro) -, a presença de imigrantes

100 que se chama aqui de "região metropolitana de Joinville" equivale ao que o PNUD chama de Núcleo Metropolitano do Norte/Nordeste Catarinense. Note-se inclusive que, segundo o próprio PNUD, as regiões limitrofes à de Joinville, Núcleo Metropolitano do Vale do Itajaí e Núcleo Metropolitano de Florianópolis, foram classificadas respectivamente como segunda e primeira em IDH no ranking nacional. Fato este que faz com que o estado de Santa Catarina tenha, apenas no entorno de sua porção leste, as três primeiras regiões metropolitanas em IDH no Brasil.

11 "Além de computar o PIB per capita, depois de corrigi-lo pelo poder de compra da moeda de cada país, o IDH também leva em conta dois outros componentes: a longevidade e a educação. Para aferir a longevidade, o indicador utiliza números de expectativa de vida ao nascer. O item educação é avaliado pelo índice de analfabetismo e pela taxa de matrícula em todos os níveis de ensino. A renda é mensurada pelo PIB per capita, em dólar PPC (paridade do poder de compra, que elimina as diferenças de custo de vida entre os países). Essas três dimensões têm a mesma importância no índice, que varia de zero a um" (PNUD, 2008).

12 Sobre a evolução histórica das atividades econômicas em Joinville, sugere-se consultar Stallivieri (2004). 
com conhecimentos industriais e os fortes laços com os desenvolvimentos técnicos provenientes da Alemanha (importante produtora de bens eletrometal-mecânicos) determinaram que a economia local se desenvolvesse, principalmente, em torno das atividades do complexo eletrometal-mecânico.

Stallivieri (2004:59) afirma existir nesse complexo industrial uma especialização superior à média nacional. Assim sendo, segundo o autor, essas atividades eram responsáveis, em 2002, por $25,12 \%$ do emprego total da região e $27,83 \%$ da massa salarial local, o que corresponde a $12,22 \%$ dos empregos nacionais e $5,89 \%$ do total de empresas do complexo no país.

A consolidação da indústria eletrometal-mecânica na região de Joinville permitiu que toda economia local se dinamizasse a ponto, inclusive, de garantir o desenvolvimento regional durante um longo período. No entanto, as transformações recentes do capitalismo brasileiro, principalmente nos anos 80 e 90 do século passado, provocaram mudanças estruturais nas empresas joinvillenses desse complexo industrial. O surgimento da indústria de software de Joinville encontra-se no interior de uma dinâmica conhecida como reestruturação produtiva, que, por sua vez, implicou e tem implicado processos de terceirização e downsizing nas firmas. Esse movimento ocorre em direção à externalização de todas as atividades corporativas que não se encontram inseridas nas core competences das grandes empresas do complexo eletrometal-mecânico da região.

A mudança do paradigma organizacional, ao impulsionar as empresas do referido complexo industrial em direção à terceirização e por isso à subcontratação das atividades que não se constituíam em atividades centrais, permitiu que o processamento de dados, antes realizado em grande parte por computadores pertencentes às firmas, passasse a ser contratado no mercado. Surgem assim as primeiras firmas joinvillenses produtoras e prestadoras de serviços na área de software. Num momento posterior, ocorre a transposição das fronteiras regionais e as firmas de desenvolvimento de software passam a conquistar mercados em todo território nacional.

Contudo, a gênese da indústria de software em Joinville não pode apenas ser associada ao processo de reestruturação produtiva da indústria eletrometalmecânica, iniciado ainda em meados da década de 80 do século XX, ela está também relacionada aos processos históricos de barateamento e miniaturização do hardware e ao fim da política de reserva de mercado da indústria de informática. Segundo Nicolau, Campos e Cário (2000:39), a indústria de software de Joinville passou por três fases distintas até se consolidar como um importante aglomerado produtor de software. 
A primeira fase ocorre nos anos 70 do século $\mathrm{XX}$, quando as empresas do complexo eletrometal-mecânico da região realizaram elevados investimentos na constituição de seus setores de processamento de dados, os quais funcionavam com base em grandes mainframes. Nesse mesmo contexto, as pequenas e médias firmas, que não possuíam recursos suficientes para a compra de grandes computadores, demandavam os serviços ofertados pelos bureaux de processamento de dados, que aos poucos se estabeleciam na região.

Por volta da década de 1980, o barateamento e a diminuição do porte dos equipamentos de informática impelem as firmas dos mais variados tamanhos e setores de atividades a comprar computadores e informatizar suas rotinas, fato este que acaba por criar uma demanda capaz de alimentar as empresas locais de desenvolvimento de softwares. Acontece, nessa fase, a criação das primeiras empresas desenvolvedoras de software, as quais foram formadas, em grande medida, por ex-funcionários oriundos das divisões de processamento de dados das grandes empresas e dos bureaux. Devido à reserva de mercado, que protegia a indústria nacional de informática, que vigorou até início da década de 1990, as recém-criadas empresas de software se desenvolveram protegidas dos produtos e das empresas estrangeiras, fornecendo as linhas de programação para as diversas firmas da região que informatizavam seus processos produtivos.

Num terceiro momento, já em meados da década de 90 do século XX, com o fim da reserva de mercado, ${ }^{13}$ as empresas que antes produziam apenas softwares do

13 Conforme Garcia e Roselino (2004:179), até 1993, data em que efetivamente as novas regras para o setor de informática entram em vigor, o governo brasileiro, através da lei n.7.232 de 29 de outubro de 1984, garantia reserva de mercado às empresas que comercializassem e produzissem: (1) semicondutores; (2) hardwares em geral; e (3) softwares. A lei que estabelecia a reserva de mercado garantiu às empresas nacionais oito anos de proteção diante das empresas estrangeiras em praticamente todos os produtos e serviços relacionados às atividades de informática. Apoiava-se inclusive uma política de proteção ao similar nacional. É nesse contexto que se cria a SEl (Secretaria Especial de Informática), órgão responsável pela então política de informática no Brasil. Contudo, adiante da mudança do paradigma político em fins da década de 1980 e inícios da década de 1990, ocorre um movimento em direção à flexibilização e à desregulamentação da economia, e a SEI passa a perder seus poderes e toda a proteção existente aos produtores de bens e serviços na área de informática gradativamente desaparece. As políticas de reserva de mercado dão lugar a incentivos fiscais vinculados às atividades de pesquisa e desenvolvimento realizadas no país e ao estabelecimento de barreiras tarifárias. Os produtores de software, nesse sentido, veem-se pela primeira vez competindo com grandes companhias estrangeiras, que passam a se sediar no país. No caso da indústria de software, até 1992, era praticamente proibida a entrada de empresas estrangeiras e a concessão de licenças de uso de linhas de programação desenvolvidas por estas. Após essa data, a entrada de empresas estrangeiras e a licença de uso foram liberadas, possibilitando, inclusive, que as filiais de empresas multinacionais se beneficiassem de praticamente todos os incentivos anteriormente direcionados às empresas nacionais. A fim de permitir uma melhor situação concorrencial diante dos bens e serviços estrangeiros, agora permitidos de entrar no mercado brasileiro, é criado o projeto DESI (Desenvolvimento Estratégico em Informática), que, dentre outros projetos prioritários, criava a SOFTEX (Associação para a Promoção da Excelência do Software Brasileiro). O programa SOFTEX, criado por sua vez com o objetivo primeiro de estimular a consolidação de uma indústria de software brasileira voltada para as exportações, passa atualmente a buscar outro foco, qual seja: promover a qualificação do software nacional. 
tipo ERP ${ }^{14}$ são forçadas, em virtude da entrada de concorrentes internacionais, a buscarem novos nichos de mercado. A infraestrutura de fomento do sistema local passa a surgir nessa fase, criam-se associações de classe, organizações setoriais e cursos de educação na área de informática nos mais variados níveis.

No contexto da breve história do software em Joinville, os seguintes fatos devem ser levados em consideração:

1) preferência aos produtores locais (dada a elevada necessidade de compartilhamento de informações estratégicas, os empresários locais preferiam-se relacionar comercialmente com desenvolvedores locais de softwares);

2) informatização das atividades comerciais da região (o desenvolvimento socioeconômico e a revolução da microinformática fomentaram a utilização de softwares nas mais diversas atividades econômicas; assim, ocorre durante a década de 1990 o surgimento de empresas especializadas em softwares para a gestão de escolas, de frotas, de bibliotecas, entre outras);

3) qualificação da mão de obra (as demandas geradas pelas recém-criadas empresas de software da região levaram à criação de inúmeros cursos de informática, oferecendo, em 1999, um total de 500 vagas/ano);

4) criação das primeiras organizações de fomento setorial (em 1995 e 1999 foram criadas, respectivamente, as organizações de fomento setorial SOFTVILLE, ${ }^{15}$ agente SOFTEX do município e MIDIVILLE, ${ }^{16}$ gerida pelo SENAI ${ }^{17}$ ).

Em resumo, as grandes empresas que possuíam seus próprios equipamentos de informática, impelidas pela reestruturação produtiva, passam a externalizar as atividades de processamento de dados, que antes eram internas a elas. Esse processo só se inicia na medida em que ocorre um barateamento e a redução de tamanho dos equipamentos necessários, permitindo assim que antigos funcionários das grandes empresas iniciem seus próprios negócios, desenvolvendo softwares primeiramente para suas ex-empresas. Com o passar do tempo, a difusão da microeletrônica se

\footnotetext{
14 Segundo Simioni (2001:53), o sistema de gestão empresarial denominado Enterprise Resource Planning - ERP é um tipo especial de software que tem por objetivos (1) "automatizar e integrar a maioria dos processos empresariais"; (2) promover "a coerência vertical das decisões da firma usuária"; (3) agilizar o "atendimento dos consumidores finais com produtos personalizados"; e (4) eliminar "todos os processos que apenas agregam custos ao produto". 15 Fundação para o Fomento do Software de Joinville.

16 Microdistrito Industrial de Joinville.

17 Serviço Nacional de Aprendizagem Industrial.
} 
torna tal nas atividades econômicas da região, que surgem novos nichos de mercado, criando uma demanda para os recém-iniciados empreendimentos. Por fim, a abertura do mercado brasileiro e a consequente entrada de produtores de software ERP estrangeiros fazem com que as empresas de software da região procurem explorar esses novos nichos de mercado criados em função também da difusão das tecnologias de informação e comunicação.

A competência adquirida no fornecimento de softwares do tipo ERP para as atividades industriais típicas da região acaba por criar elevada competitividade das firmas locais, uma vez que as demandas internas à região eram provenientes inclusive de grandes firmas do complexo eletrometal-mecânico, que exigiam elevados padrões de qualidade, preços competitivos e intensos conhecimentos das rotinas. Logo, a proximidade com as demandas das firmas locais e a capacidade em atendê-las de forma satisfatória permitiram às empresas desenvolvedoras de software da região inserção nos mercados nacional e latino-americano, primeiramente em setores tradicionais da economia e posteriormente num leque abrangente de atividades econômicas. Nesse sentido, numa indústria marcada pela constante troca de informaçôes em vias virtuais, os concorrentes das firmas de Joinville extrapolam as fronteiras geográficas da região. Muito embora as empresas da cidade concorram entre si, elas também enfrentam a concorrência das empresas nacionais e multinacionais.

Portanto, o surgimento da indústria de software em Joinville ocorre por meio de um processo endógeno impulsionado por mudanças técnicas provindas da indústria de informática (redução de tamanho e barateamento dos equipamentos), econômicas (processos de reestruturação produtiva das empresas do complexo eletrometal-mecânico) e políticas (fim da reserva de mercado).

\section{Atual dinâmica inovativa da indústria de software de Joinville (SC)}

Em 2005, data do mapeamento realizado em Joinville, a infraestrutura de apoio à indústria local de software encontrava-se em elevado estágio de desenvolvimento e apresentava um potencial de interação muito relevante. Para um universo de 148 empresas de software (Prefeitura Municipal de Joinville, 2005), existem 11 organizações de ensino (SENAI - JL, ${ }^{18}$ CTC - UDESC, ${ }^{19}$ SOCIESC,${ }^{20}$ Colégio Elias Moreira, 
UNIVILLE, ${ }^{21}$ ACE, ${ }^{22}$ UTESC, ${ }^{23}$ Colégio Nova Era, FCJ, ${ }^{24}$ IESVILLEE $^{25}$ e FATESC ${ }^{26}$ ), que oferecem ao todo 1.659 vagas para as áreas de informática, inclusive para a área de programação, 2 organizações de fomento setorial local (SOFTVILLE e MIDIVILLE), 2 organizações de fomento setorial de nível estadual e nacional (SUCESU ${ }^{27}$ e ASSESPRO ${ }^{28}$ ) e 3 organizaçôes de classe (AJORPEME, 29 SEPIJ ${ }^{30}$ e SINDPD $^{31}$ ). No âmbito das instituiçōes, foram observados 2 programas de desenvolvimento do setor (PLATIC ${ }^{32}$ e o Planejamento Estratégico da Cidade de Joinville) e 2 leis municipais (lei n. $3.598^{33}$ e lei n. $5.178^{34}$ ), que influenciam direta ou indiretamente as atividades de produção e prestação de serviços em software realizadas na cidade de Joinville e em seus entornos. Tem-se, assim, um conjunto de organizações e instituições que existe para fomentar e executar pesquisa, formar e treinar recursos humanos e para coordenar políticas.

Através da realização de entrevistas a uma amostra selecionada de firmas, notou-se um pequeno grau de interação entre as empresas de software. Apesar de se falar em um sistema de inovação da indústria de software na região, cujo controle e gerenciamento formal e explícito seria feito pela SOFTVILLE, o sistema local de inovação, em realidade, caminha ao sabor dos estímulos internos a cada firma, num movimento conservador diante dos desafios colocados externamente. Portanto, embora exista uma organização teoricamente encarregada da gestão do sistema, ele, bem ou mal, tem-se autogerido, as firmas da amostra, como se verá adiante, apesar do aparato organizacional e institucional existente, realizam suas atividades produtivas de maneira isolada, dependendo muito pouco de relaçōes de cooperação, seja com outras firmas, seja com universidades, organizaçóes de fomento setorial ou órgãos de classe.

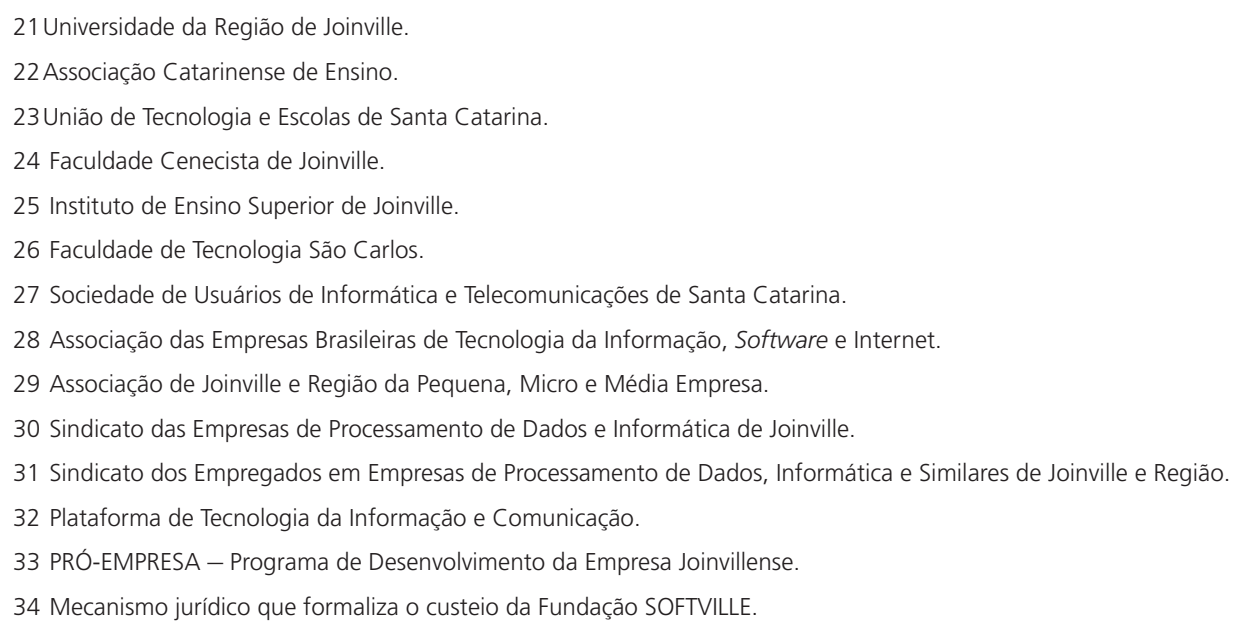


A partir das entrevistas realizadas, é possível afirmar ainda que o papel prático das universidades - importantes organizações em sistemas locais de inovação - está restrito à formação de mão de obra para as empresas do sistema. Inexiste cooperação para a pesquisa em áreas relevantes para indústria de software, e o horizonte de curto prazo permeia as relações entre as universidades e as outras organizaçôes existentes.

As universidades mais antigas e tradicionais (UDESC, SOCIESC e UNIVILLE) foram importantes para a formação da SOFTVILLE e do PLATIC, no entanto, devido a inúmeros problemas (falta de recursos, falta de governança para a cooperação, excesso de burocracia etc.), suas potencialidades encontram-se subutilizadas. Existem ainda muitas faculdades e universidades que possuem pouca ou nenhuma tradição no ensino das ciências da computação, mas, aproveitando-se de um nicho de mercado não atendido, se lançam no ensino da programação. Em linhas gerais, no que tange às universidades mais tradicionais, percebeu-se a existência de um discurso formal em prol da pesquisa, cuja prática não ultrapassa a formação da mão de obra e se restringe a algumas atividades esporádicas de consultoria.

Assim sendo, como será discutido a seguir, a infraestrutura de apoio à indústria de software local, apesar de contar com um número significativo de organizaçóes e umas poucas instituições, não tem conseguido articular o sistema local de modo a utilizar as potencialidades inerentes à cada organização e instituição isoladamente considerada.

\subsection{Definição da amostra}

As informaçōes sobre as empresas de software da região metropolitana de Jonville, ${ }^{35}$ bem como sobre a infraestrutura de fomento a estas, foram extraídas por meio de pesquisa de campo realizada ao longo de todo o mês de junho de 2005, a partir da qual aplicaram-se questionários estruturados a uma amostra intencional de dez firmas e quatro organizações de fomento local. Nesse sentido, também foi relevante a análise de documentos e dados coletados diretamente em órgãos municipais.

35 Do total das dez firmas que compõem a amostra, nove encontram-se na cidade de Joinville e uma na cidade de Jaraguá do Sul, com a qual Joinville faz fronteira a oeste. A inclusão da firma de Jaraguá do Sul se justifica, pois procurou-se considerar neste trabalho um conceito de região que incorporasse inclusive as áreas de influência imediatamente próximas da cidade objeto de estudo. Dessa forma, pode-se afirmar que, no interior da região metropolitana de Joinville, as dinâmicas históricas, econômicas, produtivas e inovativas são únicas; assim sendo, as análises aqui feitas valem para o conjunto das cidades no entorno imediato desta. Mesmo porque as firmas de software existentes em Jaraguá do Sul, dadas as suas relações de concorrência e cooperação e a inexistência de um sistema de inovação específico, são parte integrante do sistema local de inovação da indústria de sofwtare de Joinville. 
Considerando que este trabalho procura analisar seu objeto de estudo a partir da abordagem neo-schumpeteriana de sistemas de inovação, os critérios de seleção da amostra procuram representar a capacidade interativa das firmas da indústria de software da região em questão.

Como primeiro critério, procuram-se empresas de maior faturamento associadas à SOFTVILLE, em seguida, optou-se por entrevistar empresas associadas a essa organização de fomento, que, independentemente do faturamento, se dispusessem a conceder entrevista e a receber visita in loco.

Nas empresas da amostra, estão firmas que atuam em diferentes mercados de software. Assim se tem desde empresas desenvolvedoras de software pacote - com atuação nos mercados latino-americanos - quanto empresas de software embarcado e de serviços de software comercializados quase exclusivamente na região de Joinville. Alcançou-se, então, o número de dez empresas, todas associadas à SOFTVILLE, que juntas representavam, no ano de 2004 , em torno de $67 \%$ do faturamento total do aglomerado. ${ }^{36}$ Por outro lado, considerando os dados apresentados por Softex (2005), o faturamento das empresas da amostra, estimado a partir das entrevistas, representava, em 2004, 2,4\% do total do setor no país, enquanto o aglomerado como um todo, e não apenas a amostra, participava, no mesmo ano, com 3,6\% do faturamento nacional do setor. Do total das empresas da amostra, três empresas eram classificadas como microempresas, quatro empresas como pequenas, uma empresa classificada como média e duas empresas como grandes. ${ }^{37}$

Entrevistaram-se, ainda, as duas únicas organizaçōes de fomento local à indústria de software, uma organização de classe (única disposta a conceder entrevista) e uma organização de ensino e pesquisa, totalizando quatro organizaçóes relacionadas com o sistema de inovação local. A escolha da organização de ensino e pesquisa se pautou por indicações de relevância dela colhidas ao longo das entrevistas. Importante lembrar que, em dois casos, o mesmo indivíduo atuava em diferentes organizações.

\subsection{Dados econômicos gerais: origens, faturamento, marketing e mercado de trabalho}

Considerando a amostra de firmas e as entrevistas realizadas em junho de 2005,

36 Calculado com base nos dados coletadados nas entrevistas e em polos de exportação de software (2005).

37 Segundo o MDIC - Ministério do Desenvolvimento Indústria e Comércio Exterior (2002:2), os critérios utilizados pelo SEBRAE (Serviço Brasileiro de Apoio às Micro e Pequenas Empresas) para a classificação do tamanho das firmas são: microempresa (até 9 empregados), pequena empresa (de 10 a 49 empregados), média empresa (de 50 a 99 empregados) e grande empresa (mais de 99 empregados). 
a comprovação da existência de um vigoroso aglomerado do setor de software é dada pelo número de empresas abertas por ex-funcionários de outras empresas de informática da região, $50 \%$ da amostra, conformando um processo de spin-offs que é característico do setor. Por outro lado, existem poucos spin-offs de universidades da região. Apenas 10\% dos proprietários das empresas da amostra provinham de organizações de ensino e pesquisa. No contexto da origem dos proprietários das empresas da amostra, destacam-se ainda as firmas abertas por ex-funcionários de outras empresas da região, $30 \%$ da amostra, notadamente ligadas ao complexo eletrometal-mecânico.

Apesar de a produção de serviços de software ser a principal atividade para $70 \%$ das firmas da amostra, a produção de software pacote ocupava, em 2004, a primeira posição em termos de faturamento, atingindo o montante de R 194 milhões, ou seja, $96,7 \%$ do faturamento total da amostra. Contrariamente ao que é verificado em Stefanuto (2004) sobre a indústria nacional, na amostra, a principal fonte de recursos é proveniente do desenvolvimento de software pacote, e apenas 3,3\% do faturamento total está relacionado ao fornecimento de serviços de softwares. Mesmo assim, em número de empresas, o aglomerado produtivo de software de Joinville acompanha a realidade brasileira, tendo mais empresas desenvolvedoras de serviços de software do que de software pacote. O elevado peso do software pacote no faturamento total da amostra se deve à presença das únicas duas grandes firmas do aglomerado que são produtoras exclusivas de softwares pacote. Importante lembrar que o faturamento total da amostra selecionada representava, em 2004, 67\% do faturamento total do aglomerado, portanto, a relevância do software pacote no aglomerado de empresas da região é realmente considerável.

Não obstante, e considerando o total de empresas de software da região (universo e não apenas a amostra), pode-se afirmar que houve uma desconcentração do faturamento total do aglomerado. Enquanto em 1999 as duas maiores empresas representavam aproximadamente $90 \%$ do faturamento total, ${ }^{38}$ no ano de 2004 sua participação no conjunto do aglomerado cai para cerca $65 \%$.

Quanto à capacidade de alavancagem financeira, pode-se afirmar que a falta de um caráter mais profissional e menos familiar/informal das pequenas empresas, aliado a um passado ainda recente de ambiente macroeconômico instável, às altas taxas de juros e às necessidades de garantias reais para empréstimos bancários, forçou as empresas da amostra a utilizar os recursos próprios e ou de familiares como principal fonte de financiamento, fato este que se assemelha à realidade nacional. 
Assim, o papel desempenhado pelo Estado, por bancos privados e, finalmente, por representantes do venture capital é mínimo. ${ }^{39}$ Não obstante, $100 \%$ das empresas entrevistadas afirmaram que realizarão investimentos nas mais diversas atividades nos cinco anos seguintes.

As duas maiores firmas da amostra são justamente aquelas em que havia concentração de esforços na produção de software pacote, refletindo uma dinâmica própria do subsetor. Essas empresas realizaram relevantes investimentos em marketing e em canais de distribuição.

Por outro lado, na medida em que boa parte das firmas entrevistadas são de pequeno porte e prestadoras de serviços de software, as formas de divulgação de seus serviços se dão, em boa medida, por ações que impliquem baixo custo e pouca necessidade de organização. Assim, 60\% do total das empresas da amostra utiliza contatos pessoais e indicações para divulgar seus serviços; feiras e eventos são utilizados por 50\% das empresas; representantes por $20 \%$; e revistas técnicas também por $20 \%$ da amostra. Foram citados também congressos técnicos, telemarketing, Internet, folders e outdoors, utilizados em $10 \%$ dos casos. Em apenas metade das empresas entrevistadas, existe suporte de vendas formalizado, no qual consultores e franqueados provêm os serviços relacionados a essa atividade.

Apesar da significativa participação dos encargos trabalhistas nos custos totais já que o software é intensivo em conhecimento humano -, o que se verificou nas entrevistas foi que apenas uma das empresas da amostra - que possuía pessoal empregado (além dos sócios) - contratou um técnico sob o regime de cooperativas. Nas demais empresas ( $90 \%$ das empresas da amostra), 100\% do pessoal técnico está sob o regime CLT, ${ }^{40}$ deixando apenas os consultores como cooperados. Entretanto, todas as firmas visitadas possuem relações de trabalho ditas flexíveis com esses cooperados prestadores de consultoria.

Assim sendo, na medida em que as atividades se vão distanciando das core competences das firmas, espera-se que os laços trabalhistas formais se tornem rarefeitos. Segundo os empresários e diretores ouvidos, a preferência por formas típicas de contratação (CLT) se dá justamente por inúmeros problemas encontrados nas tentativas anteriores de se modificar a estrutura de emprego. Além disso, eles veem esse processo de flexibilização como ilegal e sujeito a ações judiciais.

No que tange à qualificação da mão de obra, verificou-se na amostra de firmas que 39 A Pesquisa de Inovação realizada pelo IBGE com ano base em 2005 (PINTEC 2005), que pela primeira vez incluiu a atividade de serviços, corrobora com essa informação: 97\% dos investimentos em P\&D do setor Consultoria em Software foram financiados a partir de recursos próprios, $2 \%$ pelo setor privado e $1 \%$ pelo setor público (IBGE, 2007). 40 Consolidação das Leis do Trabalho. 
1) $90 \%$ das empresas possuem $100 \%$ de seu pessoal (sócios e empregados) com curso de graduação ou cursando;

2) em $70 \%$ das empresas pelo menos uma pessoa entre sócios e empregados possui pós-graduação, e, destes, existe elevado número de indivíduos com pósgraduação nas áreas gerenciais e uns poucos em áreas relacionadas à informática.

Esse último item reflete uma preocupação crescente nas firmas entrevistadas, qual seja, a falta de conhecimentos gerenciais nos técnicos que se tornaram empresários. Contudo, em virtude da extrema velocidade das mudanças ocorridas nessa indústria e da necessidade constante de aprendizado, em 100\% dos casos existe treinamento interno destinado à atualização da mão de obra técnica.

Além disso, todas as empresas entrevistadas afirmaram que a capacidade de aprendizado, a criatividade, a disciplina e a iniciativa para a resolução de problemas são características presentes na mão de obra local. De uma maneira geral, elas acreditavam que existe bom número de técnicos e bacharéis formados nas organizações de ensino da região. Identificou-se ainda que a qualidade da formação da mão de obra tem chamado a atenção das empresas entrevistadas, uma vez que apenas parte dos recém-formados pela região é selecionada nos processos seletivos das firmas.

Não obstante a fartura de mão de obra técnica (programadores e analistas), segundo a opinião dos entrevistados reforçada pela matéria veiculada no jornal Diário Catarinense, de 23 de maio de 2005, parece haver escassez de mão de obra gerencial e de consultoria específica, além de um crescente descompasso entre a formação de mão de obra técnica e as necessidades das empresas. Constatou-se ainda que existe certa tendência ao aumento do custo da mão de obra, já que o número de profissionais realmente qualificados não era capaz de atender à demanda do mercado como um todo. Daí a necessidade de treinamento interno realizado pelas firmas. Mesmo assim, a julgar pelas afirmaçôes dos entrevistados, o trinômio custo-qualidade-quantidade da mão de obra pende a balança em favor da região de Joinville, diante das demais regiões produtoras de software do país.

\subsection{Processo inovativo e dinâmicas locais}

Quanto à dinâmica inovativa propriamente dita, observou-se que todas as empresas visitadas introduziram pelo menos um novo produto ou serviço nos últimos 12 meses, e 30\% das firmas introduziram pelo menos um novo produto e $100 \%$ delas introduziram pelo menos um novo serviço. Nesse sentido, os novos produtos foram 
registrados no INPI ${ }^{41}$ por $60 \%$ das firmas da amostra, os $40 \%$ restantes não foram registrados em qualquer outro órgão.

O elevado ritmo de mudanças exigido para a manutenção das posições de mercado das firmas nessa indústria desincentivou consideravelmente estas a buscarem formas legais de proteção. Em Joinville, as empresas preferem, portanto, investir seus esforços no atendimento das necessidades dos clientes e na promoção de constantes melhorias do que incorrer num processo de formalização legal do produto ou serviço desenvolvido, mesmo porque há evidências de que o software produzido em Joinville é de baixo grau de novidade, principalmente, diante dos mesmos produtos e serviços existentes no mercado internacional. Não obstante, a preferência pelo registro ocorre mais nas empresas desenvolvedoras de software produto, já nas firmas especializadas em serviços, cujas soluçōes comercializadas são particulares à relação com o cliente, não existe preocupação em registrar os possíveis produtos e/ou os serviços desenvolvidos.

Mesmo num contexto de elevada necessidade de introdução de inovações, constatou-se a virtual inexistência de relação das empresas com qualquer organização de pesquisa, sejam elas estaduais, nacionais ou internacionais. Dessa forma, ao contrário do que rege a literatura especializada, o papel das universidades no fornecimento de conhecimentos científicos e tecnológicos está entre os menos citados, perdendo, por exemplo, para a Internet, periódicos e concorrentes (Figura 1). Apesar da relevância da formação de mão de obra, o baixo nível de interação com organizaçôes de lógica acadêmica não se verifica apenas quando tomados os dados coletados nas entrevistas; a partir também da análise histórica, já é possível inferir a pequena participação relativa dessas organizaçôes na própria dinâmica de surgimento das empresas do setor na região.

No entanto, o processo de aprendizagem do tipo learning by interacting ${ }^{42}$ advindo das relaçôes com os clientes mostra-se extremamente relevante para a dinâmica inovativa das empresas da amostra. Bem acima da mesma taxa para o setor no Brasil, ${ }^{43}$

41 Instituto Nacional de Propriedade Industrial.

420 processo de aprendizado conhecido na literatura econômica como learning by interacting constitui-se numa forma externa de aprendizado, cujos elementos fundantes são a comunicação e a troca de informações sobre as tecnologias empregadas em novos produtos e processos. Para Lundvall (1988), em ambientes de rápida mudança técnica, as firmas veem-se impelidas em interagir; essa interação leva a um tipo especial de aprendizado, que ocorre por meio dos relacionamentos entre usuários e produtores. De maneira geral é um processo social, cujos desenvolvimentos e robustez da relação podem culminar em ganhos que ultrapassam as vantagens puramente econômicas (Campos et al., 2003).

43 Segundo a PINTEC 2005, 47,35\% das empresas inovadoras de consultoria em software afirmaram serem os clientes fontes importantes de informação para a inovação. 
$100 \%$ das firmas entrevistadas salientaram que as demandas dos clientes são fontes importantes ou muito importantes para a promoção de inovações e melhoramentos nos produtos. As feiras, os congressos, a P\&D e a Internet também se destacam como fontes de informações pertinentes para a geração de inovações.

O processo produtivo das firmas de software, de uma maneira geral, confundese com as atividades de pesquisa e desenvolvimento. Não há uma clara distinção entre atividades rotineiras e atividades de P\&D. ${ }^{44}$ Mesmo assim, identificou-se que a pesquisa e o desenvolvimento realizados nas firmas visitadas são extremamente aplicados, visando a objetivos previamente estabelecidos através principalmente da identificação baseada nas necessidades do mercado. Ou seja, não se encontrou nas firmas entrevistadas um processo de busca dissociado das imediatas necessidades do mercado, de maneira que as inovaçôes desenvolvidas quase sempre são do tipo incremental. ${ }^{45}$

$\mathrm{Na}$ análise da Figura 1, além da participação dos clientes, chama a atenção o elevado percentual relativo de empresas que afirmaram ser a P\&D fonte, pelo menos frequente, de geração de inovações. Um olhar mais cuidadoso deve ser dado a esse percentual, já que, nas entrevistas concedidas in loco, se percebeu a dificuldade de avaliar e, por isso, diferenciar o que se tratava de pesquisa e desenvolvimento - tal como entendido, por exemplo, pelo Manual de Oslo - e a atividade rotineira de programação. Assim, possivelmente, a relevância da $P \& D$ nas empresas da amostra foi superdimensionada. Assim sendo, não foi possível avaliar os gastos percentuais em atividades de pesquisa e desenvolvimento sobre o valor adicionado, o que permitiria avaliar o grau de intensidade tecnológica das firmas estudadas.

Devido a essa intensa necessidade de introdução de inovações, sejam radicais ou incrementais, o próprio desenvolvimento da firma depende de sua capacidade de produzir novos produtos e ou serviços. Assim sendo, dentre os principais entraves encontrados pelas firmas entrevistadas a respeito de sua capacidade de inovar, destacamse a dificuldade para promover relaçôes de cooperação com outras empresas (90\%)

44 O Manual Frascati afirma que um projeto de P\&D em software é aquele cuja conclusão depende de um avanço técnico e/ou científico, tendo como objetivo, portanto, a resolução sistemática de alguma incerteza científica e ou tecnológica (OCDE, 2002:46).

45 De acordo com Freeman e Perez (1988), as inovações podem ser divididas, grosso modo, em incrementais e radicais. As inovações incrementais surgem a partir de melhorias em produtos ou processos já existentes, não possuem a capacidade de modificar as estruturas econômicas nas quais estão inseridas e se dão, por via de regra, no interior de um já estabelecido paradigma técnico-econômico. Suas possibilidades de lucro são limitadas e seu surgimento é relativamente comum. As inovações radicais constituem-se em novidades comercialmente viáveis que, a partir de sua difusão, são capazes de modificar a estrutura econômica da qual pertencem, gerando, inclusive, elevado poder de monopólio às firmas inovadoras. Frequentemente essas inovações desafiam o paradigma técnico-econômico vigente e, quando surgem concentradas, são capazes de transformar todo o conjunto da economia. 
FIGURA 1

Empresas que afirmaram serem as seguintes fontes de informação muito frequentes ou frequentes para a geração de inovações, por tipo de informação - Joinville, 2005

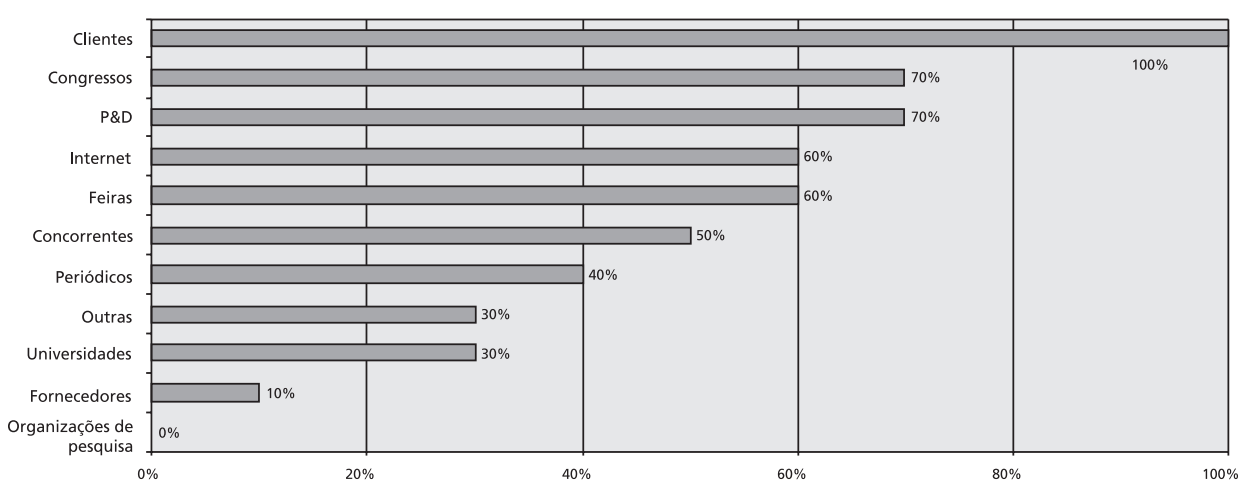

Fonte: pesquisa de campo.

e a dificuldade de obtenção de recursos financeiros (60\%). A mão de obra qualificada e seu preço foram citados como entraves muito frequentes ou frequentes em apenas $30 \%$ e $10 \%$ dos casos, respectivamente. Importante ressaltar que, para apenas $20 \%$ das empresas da amostra, a complexidade tecnológica do produto é tida como um entrave frequente ou muito frequente para os processos de inovação.

Considerando-se que $90 \%$ das empresas da amostra afirmaram enfrentar dificuldades na formação de redes de cooperação, torna-se clara a falta de articulação ou sinergias horizontais - não obstante os esforços da SOFTVILLE e AJORPEME no interior do sistema de inovação estudado. Dado o pequeno tamanho das firmas que compóe boa parte da amostra, ainda existe muita personificação da firma em torno de seu proprietário, e a comunicação entre as empresas se dá com muita desconfiança. O conhecimento, portanto, é gerado e difundido em boa medida por meio da rotatividade da mão de obra, que, ao incorporar conhecimento tácito numa determinada firma, é capaz de levá-lo a outras empresas em que por ventura venha a atuar.

Outro fato relevante encontrado nas entrevistas e relacionado aos entraves do processo inovativo diz respeito ao total desconhecimento das firmas sobre a existência das instituições de fomento local disponíveis para elas. Assim, 100\% das empresas da amostra desconhecem completamente os mecanismos legais e os projetos públicos locais destinados ao fomento de seu setor de atuação. 
FIGURA 2

Empresas que afirmaram ser as seguintes vantagens provenientes da localização na região muito importantes ou importantes - Joinville, 2005

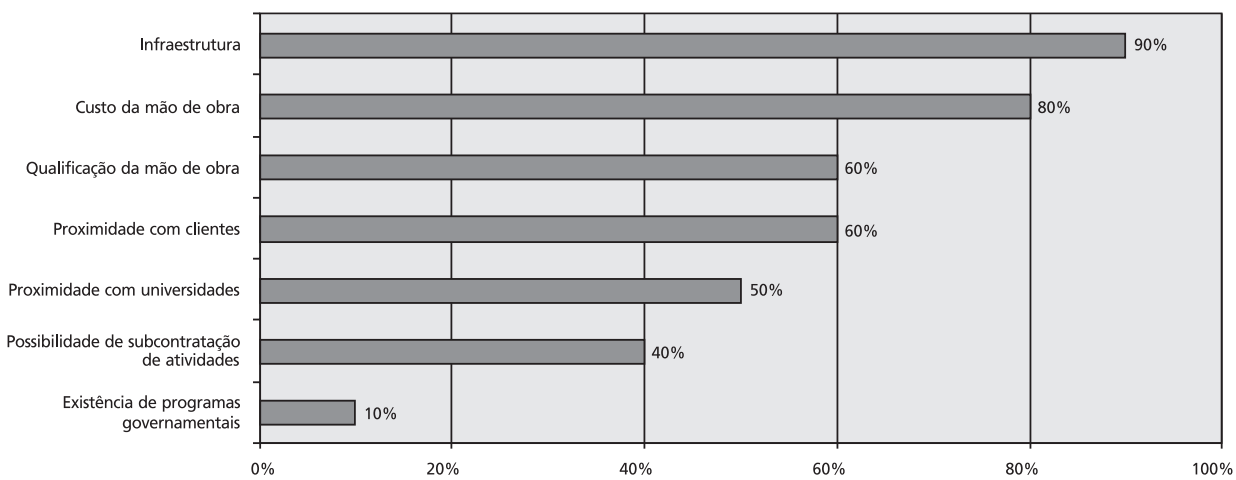

Fonte: pesquisa de campo

No que tange ao componente local, é importante notar que a infraestrutura da região, o baixo custo relativo da mão de obra e a qualificação desta foram relacionadas como as principais vantagens da localização na região de Joinville. A proximidade com universidades e centros de pesquisa foi citada como uma vantagem associada à região por $50 \%$ da amostra. Identificou-se ainda que a pertinência das organizações de ensino superior está relacionada à formação de mão de obra e não à troca de informaçôes ou atividades conjuntas de pesquisa.

Destaca-se inclusive, nesse sentido, a infraestrutura local, que, para $90 \%$ das firmas entrevistadas, se constituía numa vantagem importante ou muito importante associada à localização na região (Figura 2). Esse alto índice de respostas positivas referentes à infraestrutura local se deve, em boa medida, aos fatos, quase todos já mencionados, de que

1) a cidade de Joinville é a maior do estado, sem que isso implique elevadas deseconomias de aglomeração; ${ }^{46}$

2) é entrecortada pela recém-duplicada BR 101;

3) se localiza a meio caminho de Curitiba e Florianópolis;

4) possui o segundo melhor IDH metropolitano do país. 
Identificou-se inclusive que a existência dessa infraestrutura local associada à presença de mão de obra qualificada e barata podem tornar Joinville, dentro em breve, um importante centro de atração de investimentos na área de software. ${ }^{47}$

Não obstante as facilidades locais, a ausência da participação de atividades de maior dinâmica científica faz com que o conhecimento novo se origine de maneira tácita, incorporada nos técnicos (programadores e analistas), num misto de formação escolar e vivência de trabalho. Em que pese a alta relevância do relacionamento com os clientes, os esforços de pesquisa não dependem de máquinas ou equipamentos, mas de pessoas, e mais intensivamente de mão de obra qualificada e criativa. As parcas relações com organizaçōes de ensino e pesquisa permitiram justamente fortalecer esse quesito, qual seja: o de formar mão de obra qualificada e barata, principal insumo da indústria de softwares em Joinville.

Dessa forma, esse sistema não tem por objetivo o desenvolvimento científico e técnico da área de programação, mas a colocação no mercado de produtos com perspectivas de rápido retorno comercial. As atividades de pesquisa e desenvolvimento são, portanto, voltadas à aplicabilidade e não à exploração das fronteiras das ciências da computação. Identificou-se ainda que o diferencial buscado pelas firmas se encontra não no desenvolvimento de novas linhas de programação, mas sim na completa adequação às demandas dos clientes, ou seja, o ponto relevante não é técnico (produzir linhas de programação), mas sim fazer com que a realidade de empresas pertencentes a diferentes setores econômicos possa ser codificada a partir das ferramentas de amplo conhecimento na região.

Apesar de essas ferramentas de programação exigirem certo nível de conhecimento para sua manipulação, a parte crítica dos trabalhos está relacionada ao bom entendimento das atividades econômicas nas quais elas serão aplicadas. Assim, tão importante quanto a competência nas ferramentas de informática é a competência nas mais diversas áreas em que os softwares serão empregados. Há, por conseguinte, nas firmas entrevistadas, preocupação em se conhecer em profundidade a realidade dos potenciais clientes.

A Figura 3 demonstra que os clientes são os principais parceiros das empresas de software, os quais, de maneira geral, se encontram fora do âmbito do sistema de inovação estudado, de forma que as redes de relacionamento extrapolam os limites geográficos da região.

47 De acordo com entrevista realizada com um dos sócios-proprietarios, a segunda maior empresa do sistema local econtrava-se em pleno processo de aquisição por outra grande firma de software com sede na cidade de São Paulo, e a firma compradora pretendia, em virtude do valor da mão de obra, tranferir todas as suas atividades de programação mais básicas para a cidade de Joinville. 
FIGURA 3

Empresas que afirmaram ser as relações com os seguintes atores muito frequentes ou frequentes - Joinville, 2005

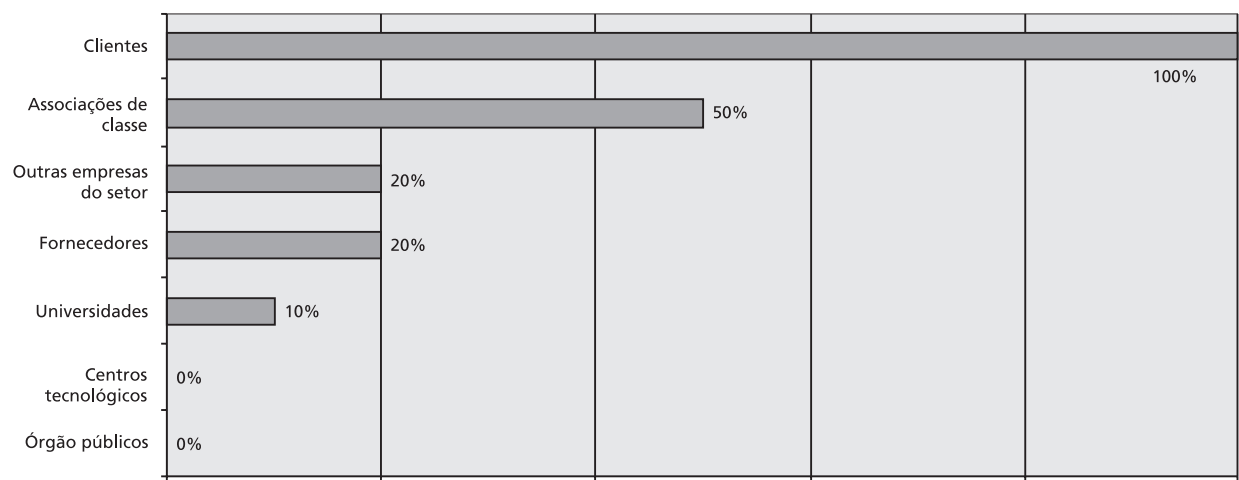

Fonte: pesquisa de campo

Para as empresas que se relacionam de alguma forma com outras empresas do setor presentes na região, a troca de informações genéricas era a principal motivação dos empresários nesse tipo de relação.

Apesar de existirem organizaçôes de fomento local e de classe, apenas metade da amostra afirmou serem frequentes ou muito frequentes as relações com elas. As relaçōes com associaçōes de classe e de fomento têm por principal objetivo a troca de informações e a realização de cursos de capacitação da mão de obra, muitas vezes necessárias às certificaçôes do processo produtivo. Foram citadas, nesse caso, as relações de cooperação visando à implantação de metodologias de qualidade em software via cursos, seminários, feiras e eventos. O perfil das empresas que buscam o auxílio das organizaçóes de fomento - leia-se SOFTVILLE - vai das micro e pequenas empresas às médias e grandes. Contudo, os objetivos das últimas são distintos das primeiras. Enquanto as micro e pequenas empresas buscam informações, apoio em feiras e eventos, as médias e grandes tendem a participar de forma mais genérica, procurando muitas vezes apenas direcionar e controlar os processos de formação de mão de obra local.

Nesse contexto, chama a atenção a virtual ausência de qualquer relacionamento com organizações de pesquisa, ou seja, acompanhando a dinâmica nacional do setor, apenas $10 \%$ das firmas da amostra afirmaram ser o relacionamento com universidades 
frequente ou muito frequente nos processos de inovação e nenhuma das firmas entrevistadas afirmou ser o relacionamento com centros tecnológicos frequente ou muito frequente para o mesmo quesito. Como já mencionado, a ausência de laços com organizações de pesquisa é uma constatação derivada tanto da análise dos dados coletados na pesquisa de campo, quanto do acompanhamento da trajetória recente da indústria de software de Joinville, ou seja, historicamente se verifica, logo no início de sua trajetória, a baixa relevância de organizações com lógica acadêmica na consolidação da então emergente atividade em Joinville. Os dados coletados apenas reforçam algo que historicamente já era uma característica da indústria de software local, ou seja, a fraca interação firmas-atividades acadêmicas e/ou universidades.

A experiência de Joinville torna-se ainda mais instigante, quando comparada às dinâmicas descritas pela literatura especializada em atividades intensivas em conhecimento, que emerge a partir dos anos 80 do século XX. Nelas, o papel desempenhado pelas organizações de pesquisa é fundamental para o amadurecimento e a consolidação de empreendimentos de base tecnológica. Inclusive, é dentro desse contexto que surgem os conceitos de incubadoras de empresas de base tecnológica e parques tecnológicos (Castells \& Hall, 1994; Benko, 1996, 1998; Malecki, 1985, Mian, 1996; Colombo \& Delmastro, 2002; Pinho, Côrtes \& Fernandes, 2002; Phan, Siegel \& Wright, 2005). Portanto, não obstante as observações internacionais e os preceitos de localização advindos dessa literatura, as atividades de produção de softwares em Joinville emergem a partir de uma dinâmica singular, na qual foram as demandas das firmas do complexo eletrometal-mecânico, e não a relação com as universidades, que nutriram as firmas de software para que elas se estabelecessem localmente e mais recentemente conquistassem mercados externos à região.

\section{Conclusões}

O sistema local estudado se insere num contexto nacional de menor comprometimento das firmas com atividades inovativas próprias e de baixa interação entre universidade e empresa, fatos estes que acabam por gerar um processo inovativo eminentemente marcado pela imitação. Assim, a dinâmica interna do sistema local estudado compartilha as características encontradas no sistema nacional de inovação brasileiro, o qual é chamado por Albuquerque (1999) em sua tipologia de sistema não maduro. Portanto, para considerar a realidade estudada - marcada pela baixa interação entre os atores relevantes, inexistência de pesquisa de longo prazo, falta de mecanismos adequados de financiamento e elevada dependência de conhecimentos 
externos à região - como um sistema de inovação, há que se compreender que o marco analítico especificado tem de ser flexibilizado, incorporando em sua abordagem os diferentes níveis tecnológicos dos países.

Portanto, se forem consideradas as organizações voltadas à produção, à comercialização e ao uso de softwares e as instituições a elas relacionadas, pode-se considerar que existe um sistema local de inovação da indústria de software em Joinville. Este é um sistema até certo ponto frágil por estar fundamentalmente baseado no desenvolvimento de software dissociado das organizaçóes de pesquisa e no qual o papel do conhecimento tácito (incorporado na mão de obra qualificada, porém barata) é exacerbado. É justamente em sua peculiaridade que reside sua fraqueza. Enquanto o sistema local estiver dissociado dos conhecimentos produzidos pelas universidades e por outras organizações de pesquisa, ele estará sujeito sempre a seguir, por meio de inovaçôes incrementais, os desenvolvimentos tecnológicos de empresas líderes. Portanto, enquanto seguidor, esse sistema se coloca numa posição de grande fragilidade em um setor de forte dinamismo tecnológico.

Nas empresas da amostra, percebeu-se elevada preocupação com os processos de geração de inovações. Porém, na medida em que a principal fonte de informações para a geração de inovações são os contatos feitos diuturnamente com os clientes, os novos produtos e serviços são, por via de regra, melhoramentos aos já existentes no mercado, uma vez que se faz presente a constante necessidade de adequar esses novos desenvolvimentos às necessidades ditadas pelos clientes. Destacam-se, nesse sentido, as constantes atualizaçôes e os novos aplicativos desenvolvidos pelas firmas de software, ou seja, também porque inexistem significativos fluxos de conhecimentos provenientes de fontes técnicas e científicas da região, inexistem inovações radicais. ${ }^{48}$ O que se verifica é um eficaz processo de geração de inovaçōes incrementais, que atendem principalmente ao mercado interno brasileiro.

Contrariamente ao mercado brasileiro de software, o sistema local de inovação da indústria de software de Joinville concentra-se, do ponto de vista do faturamento agregado, no segmento de software pacote, muito embora as firmas que exploram os serviços de software sejam maioria. Como mencionado anteriormente, as inovações produzidas são de caráter incremental, tendo as demandas dos clientes como principais motivadoras. As atualizações e novas aplicações aos softwares já existentes são exemplos típicos das atividades inovativas realizadas no sistema. As entrevistas

48 Acredita-se que o surgimento de inovações radicais não seja apenas dependente de pesquisa e/ou desenvolvimento, mas de um leque variado de fatores, dentre os quais destacam-se determinantes de ordem econômica, tal como proposto no modelo interativo de Kline e Rosemberg (1986). 
permitiram concluir que a questão estratégica para as empresas do sistema local não é a de produzir linhas de programação, mas conseguir adequá-las à realidade do setor de aplicação. Isso faz com que a inovação seja fortemente dependente do relacionamento com o cliente, o qual não necessariamente se encontra geograficamente próximo. Em verdade, apenas para o grupo formado por pequenas e microempresas existe proximidade geográfica com os clientes.

A mão de obra é fundamental para a análise do sistema considerado. As entrevistas trouxeram evidências de que ela seja barata, relativamente aos grandes centros, e de que continue sendo a principal vantagem da região diante de outros aglomerados produtores de software, apesar da qualidade dessa mão de obra estar sendo recentemente contestada pelas empresas locais. É nesse contexto de elevada relevância da mão de obra qualificada e barata que se inserem as universidades e demais organizações de ensino. Diferentemente de muitos sistemas locais de inovação de empresas intensivas em tecnologia descritas na literatura especializada, ${ }^{49}$ a indústria de software de Joinville tem sua competitividade lastreada pela mão de obra qualificada e barata e pelos processos de aprendizados realizados com seus clientes, que se constituem na principal fonte de informaçóes e de conhecimento das empresas visitadas.

Por esses motivos pode-se afirmar que o futuro próximo reserva desafios ao sistema local de inovação da indústria de software de Joinville, muitos deles relacionados ao acirramento da concorrência no mercado de software devido à entrada de grandes firmas multinacionais nos subsetores mais customizados, nos quais as relações com os clientes são fundamentais. Resta saber, portanto, em que medida as firmas desenvolvedoras de software da região estão preparadas para enfrentar esses novos desafios. Qualquer que seja a resposta a esse questionamento, deve-se considerar a elevada capacidade de transformação do tecido produtivo local e os intensos relacionamentos já consolidados das firmas de software da região com seus clientes.

49 Para as diferentes aglomerações espaciais de empresas intensivas em conhecimento, ver, por exemplo, Castells e Hall (1994) e complementariamente Albuquerque (1999). 


\section{Referências bibliográficas}

Albuquerque, E. "National systems of innovation and non-OECD countries: notes about a rudimentary and tentative 'typology", Revista Brasileira de Economia Política, v.19, n.4(76), 1999.

Ashein, B. "Industrial districts as learning regions. A condition for prosperity?", in Anais da Conference of the IGU Commission on Interdependent and Uneven Development: Global-Local Perspectives. Seoul, 1995.

Bell, R.M. "Learning and the accumulation of industrial technological capacity in developing countries", in Fransman, M.; King K. (org.), Technological capability in the Third World. Londres: Macmillan, 1984.

Benko, G. Economia, espaço e globalização na aurora do século XXI. São Paulo: HUCITEC, 1996.

"El impacto de los tecnopolos en el desarrollo regional: una revisión crítica", EURE, Santiago, v.24, n.73, p.55-80, 1998.

Breschi, M.; Malerba, F. “Sectoral innovation systems: technological regimes, Schumpeterian dynamics, and spatial boundaries", in Edquist, C. (org.), Systems of innovation: technologies, institutions and organizations. Londres: Frances Pinter, 1997.

Campos, R. et al. "Aprendizagem por interação: pequenas empresas em sistemas produtivos e inovativos locais", in Rede de pesquisa em sistemas produtivos e inovativos locais. UFRJ, 2002.

Campos, R.; Simioni, M. "Características da indústria de software em Joinville - Santa Catarina”, in Cario, S; Pereira, L; Schunemann, A. (org.), Características da estrutura de mercado e do padrão de concorrência de setores industriais selecionados de Santa Catarina. Florianópolis: Editora da UFSC, 2002.

Campos, R.; Cario, S.; Nicolau, J.A.; Vargas, G. "Aprendizagem por interação: pequenas empresas em sistemas produtivos e inovativos locais", in Lastres, H.M.M. et al., Pequena empresa: cooperação e desenvolvimento local. Rio de Janeiro: Relume Dumará, 2003.

Carlsson, B.; Jacobson, S. "Diversity creation and technological systems: a technological policy perspective", in Edquist, C. (org.), Systems of innovation: technology, institutions and organizations. Londres: Frances Pinter, 1997.

Carlsson, B.; Stankiewicz, R. "Technological systems and industrial dynamics. Implications for firms and governments", in Anais da International J.A. Schumpeter Conference, 1994. 
Carlsson, B.; Stankiewicz, R. "On the nature function and composition of technological systems", in Carlsson, B. (org.), Technological systems and economic performance. The case of factory automation. Dordrecht: Kluwer Academic Publisher, 1995.

Castells, M.; Hall, P. Tecnópolis del mundo: la formación de los complejos industriales del siglo XXI. Madri: Alianza Editorial, 1994.

Coenen, L.; Moodyson, J.; Asheim, B. "Proximities in a cross-border regional innovation system: on the knowledge dynamics of medical valley (DK/SE)", in Anais do $4^{\text {th }}$ Congress of Proximities Economics. Marseille, 2004.

Colombo, M.G.; Demastro, M. "How effective are technology incubators? Evidence from Italy”, Research Policy, v.31, p.1.103-1.122, 2002.

Cooke, P. "Regional innovation systems: an evolutionary approach", in Braczyk et al. (org.), Regional innovation systems. Londres: UCL Press, 1996.

Strategiees for regional innovation systems: learning transfer and applications. Viena: United Nations Industrial Development Organization, 2003.

Dosi, G. "Technological paradigms and technological trajectories”, Research Policy, v.11, 1982.

Edquist, C. "Systems of innovation approaches - Their emergence and characteristics", in Edquist, C. (org.), Systems of innovation: technologies, institutions and organizations. Londres: Frances Pinter, 1997.

"Empresas de tecnologia no norte de SC procuram profissionais capacitados", Diário Catarinense, Economia. Florianópolis, 23 maio, 2005.

Freeman, C. Technology and economic performance: lesson from Japan. Londres: Frances Pinter, 1987.

."Innovation in a new context", STI Review, n.15, 1995.

Freeman, C.; Perez, C. "Strutural crises of adjustment, business cycles and investment behavior", in Dosi et al. (org.), Technical change and economic theory. Londres: Frances Pinter, 1988.

Freire, E. "Inovação e competitividade: o desafio a ser enfrentado pela indústria de software", Dissertação de Mestrado em Economia, Instituto de Economia, UNICAMP. Campinas, 2002.

Galípolo, G; Fernandes, D. "Notas para uma avaliação da influência de Marx em Douglas North”, in Anais da ANPEC. Natal, 2005.

Garcia, R; Roselino, J. "Uma avaliação da lei de informática e de seus resultados como instrumento indutor de desenvolvimento tecnológico e industrial”, Gestão e Produção, v.11, p.177-185, 2004. 
Godin, B. "Science, accounting and statistics: the input-output framework", Research Policy, v.36, p.1.388-1.403, 2007.

Hatzichronoglou, T. Revision of the high-technology sector and product classification. Paris: OCDE, 1997.

Herrera, A. Ciência e política na América Latina. México: Siglo XXI, 1971.

Hircsh-Kreinsen, H. "Low-technologies: a forgotten sector in innovation policy", PROACT Conference Innovation Pressure. México, mar., 2006.

Hirsh-Kreinsen, H.; Jacobson, D.; Laestadius, S.; Smith, K. Low-tech industries and knowledge economy: state of the art and research challenges. PILOT Project. Oslo, 2003.

IBGE. Pesquisa de inovação tecnológica 2005. Rio de Janeiro, 2007.

"Produto interno dos municípios: 2002-2005", Contas nacionais. Rio de Janeiro, 2007, n.22.

"Cidades". Disponível em <http://www.ibge.gov.br/cidadesat/default.php>. Acesso em 4 de abril de 2008.

Katz, J. "Domestic technology generation in LDCs: a review of research findings", in Katz, J. (org.), Technology generation in Latin-American manufacturing industries. Londres: Macmillam, 1987.

Katz, J.; Stumpo, G. "Regimes sectoriales, productividad y competitividad internacional”, Revista de la CEPAL, n.75, p.137-159, 2001.

Kline, S.; Rosenberg, N. “An overview of innovation”, in Landau, R.; Rosenberg, N., The positive sum strategy. Washington: National Academy Press, 1986.

Lall, S. "Technological learning in the Third World: some implications of technology exports", in Stewart, F.; James J. (org.), The economics of new technologies in developing countries. Londres: Frances Pinter, p.157-179, 1982.

List, F. Sistema nacional de economia política. Cidade do México: FCE, 1979 (1841).

López, A.; Lugones, G. "Los sistemas locales en el escenario de la globalización”, Globalização e inovação localizada: experiências de sistemas locais no âmbito do Mercosul e proposiçôes de políticas de C\&T. Rio de Janeiro, Nota Técnica 15/98, 1998.

Lundvall, A. "Innovation as an interactive process: from user-producer interaction to the national system of innovation", in Dosi, G., Technical change and economic theory. Columbia University Press, 1988.

National systems of innovation: towards a theory of innovation and interactive learning. Londres: Frances Pinter, 1992. 
André Tortato Rauen, André Tosi Furtado, Silvio Antônio Ferraz Cário

Lundvall, A. et al. National systems of production, innovation and competence building. Aalborg University, 2001.

Maleki, E. J. "Industrial location and corporate organization in high technology industries", Economic Geography, v.61, n.4, p.345-369, 1985.

Maskell, P. Malmberg. "A localized learning and industrial competitiveness", Cambridge Journal of Economics, v.2, n.23, 1999.

MDIC - Ministério do Desenvolvimento, Indústria e Comércio Exterior. Secretaria do Desenvolvimento da Produção. Departamento de Micro, Pequenas e Médias Empresas. Micro, pequenas e médias empresas: definiçōes e estatísticas internacionais. Brasília, 2002.

Metcalfe, J. "Technology systems and technology policy in a evolutionary framework", Cambridge Journal of Economics, v.19, n.1, p.25-46, 1995.

Mian, S.A. "The university business incubator: a strategy for developing new research/ technology-based firms", The Journal of High Technology Management Research, v.7, n.2, p.191-208, 1996.

"Assessing and managing the university technology business incubator: an integrative framework", Journal of Business Venturing, v.12, p.251-285, 1997.

MPOG. "Classificação Nacional de Atividades Econômicas - CNAE 1.0". Disponível em <http://www.cnae.ibge.gov.br/estrutura.asp>. Acesso em 3 de fevereiro de 2008.

Nelson, R. "The co-evolution of technology, industrial structure and supporting institutions", Industrial and Corporate Change, v.3, n.1. Oxford University Press, 1994.

Nelson, R.; Mowery, D. "The global computer software industry”, in The sources of industrial leadership. Cambridge University Press, 1999.

Nelson, R.; Rosenberg, N. "Technical innovation and national system”, in Nelson, R., National innovation systems: a comparative analysis. Oxford University Press, 1993.

Nicolau, J.; Campos, R.; Barbosa, C.; Lins, H.; Cário, S. "Alta tecnologia em Santa Catarina: a nascente indústria de software", in Vieira, P. (org.), A pequena produção e o modelo catarinense de desenvolvimento. Florianópolis: SEBRAE, 2002.

Nicolau, J.; Campos, R.; Cário, S. A indístria de software de Joinville: um estudo de caso de arranjo inovativo local. Relatório final da pesquisa. Florianópolis: NEITEC-UFSC, 2000.

North, D. Institutions, institutional change and economic performance. Cambridge University Press, 1990.

OCDE. National innovation systems. Paris, 1997. 
OCDE. "Proposed standard practice for surveys on research and experimental development", Frascati manual. Paris, 2002.

Science, technology and industry scoreboard 2005. Paris, 2005.

Patel, P. K. Pavitt. "The nature and economic importance of national innovation systems", STI Review, Paris, n.14, 1994.

Phan, P.H.; Siegel, D.S.; Wright, M. "Science parks and incubators: observations, synthesis and future research", Journal of Business Venturing, v.20, p.165-182, 2005.

Pinho, M.; Côrtes, M.R.; Fernandes, A.C. "A fragilidade das empresas de base tecnológica em economias periféricas: uma interpretação baseada na experiência brasileira”, Ensaios FEE, v.23, n.1, p.135-162, 2002.

PNUD - Programa das Nações Unidas para o Desenvolvimento. "Atlas do desenvolvimento humano no Brasil”, 2003. Disponível em <http://www.pnud.org.br/atlas/PR/ Regioes_Metropilitanas_1.doc.>. Acesso em 21 de março de 2006.

"Desenvolvimento humano e IDH". Disponível em <http://www.pnud.org.br/ idh/>. Acesso em 21 de março de 2008.

"Pólos de exportação de software", Computerworld, 413, Mercado, 21 jul., 2004.

Prefeitura Municipal de Joinville. Decreto n.3.598, de 17 de novembro de 1997.

Dados da arrecadação - 2004. Empresas desenvolvedoras de software, 2005.

Rocha, I.O. Industrialização de Joinville-SC: da gênese às exportaçôes. Florianópolis: FIESCCEDIN, 1997

Rovère, R. "Paradigmas e trajetórias tecnológicas", in Pelaez, V.; Szmrecsányi, T. (org.), Economia da inovação. São Paulo: HUCITEC, 2006.

Sábato, J.; Botana, N. "La ciencia e la tecnología en el desarrollo futuro de América Latina", Revista de la Integración, p.15-36, 1968.

Salatti, R. "Flexibilização do trabalho em empresas de desenvolvimento de sistemas", Dissertação de Mestrado em Política Científica e Tecnologia, UNICAMP. Campinas, 2005.

Simioni, M. "Processo de aprendizagem produtor - Usuário nas empresas de software no município de Joinville, Santa Catarina”, Dissertação de Mestrado em Economia, UFSC. Florianópolis, 2001.

SOFTEX. Perfil das empresas brasileiras exportadoras de software. DPCT-UNICAMP, SOFTEX, 2005. 
SOFTEX-MIT. A indústria de software no Brasil-2002: fortalecendo a economia do conhecimento. SOFTEX-MIT, 2003.

Stallivieri, F. "Dinâmica econômica e a inserção de inserção de micro e pequenas empresas em arranjos produtivos locais: o caso da eletrometal-mecânica na microrregião de Joinville/SC”, Dissertação de Mestrado em Economia, UFSC. Florianópolis, 2004.

Stefanuto, G. "O programa SOFTEX e a indústria de software no Brasil”, Tese de Doutorado em Política Científica e Tecnológica, UNICAMP. Campinas, 2004.

Steinmuller, W. "The US software industry: an analyses and interpretative history", in Mowery, D., The international computer software industry. Oxford University Press, 1996.

Velasco e Cruz, S. "Teoria e história: notas críticas sobre o tema da mudança institucional em Douglas North”, Revista de Economia Politica, v.23, n.2(90), 2003.

World Bank. "World economics indicators". Disponível em <http://web.worldbank.org/ wbsite/external/datastatistics/0,,contentmdk:20899413 pagepk:64133150 pipk:641 33175 thesitepk:239419,00.html>. Acesso em 10 de março de 2008.

ENDEREÇOS PARA CORRESPONDENCIA:

André Tortato Rauen - andrerauen@ige.unicamp.br

Av. Barão de Itapura, 890 / apto 83 - Botafogo

Campinas - SP

CEP 13020-431

André Tosi Furtado - furtado@ige.unicamp.br

Departamento de Política Científica e Tecnológica

Cidade Universitária Zeferino Vaz - Distrito de Barão de Geraldo

Caixa Postal 6152 - Campinas - SP

CEP 13083-970

Sílvio Antônio Ferraz Cário - fecario@yahoo.com.br

Universidade Federal de Santa Catarina

Centro Sócio-Econômico - Departamento de Ciências Econômicas

Bloco D, 2a andar - Caixa Postal 5135 - Florianópolis - SC

CEP: $88040-970$

$48 \mathrm{O}$ RBI, Rio de Janeiro (RJ), 8 (2), p.437-480, julho/dezembro 2009 